\title{
High-Resolution Ensemble HFV3 Forecasts of Hurricane Michael (2018): Rapid Intensification in Shear
}

\author{
ANDREW T. HAZELTON \\ Cooperative Institute for Marine and Atmospheric Studies, University of Miami, and NOAA/Atlantic Oceanographic \\ and Meteorological Laboratory, Hurricane Research Division, Miami, Florida \\ XUEJIN ZHANG AND SUNDARARAMAN GOPALAKRISHNAN \\ NOAA/Atlantic Oceanographic and Meteorological Laboratory, Hurricane Research Division, Miami, Florida \\ WILLIAM RAMSTROM \\ Cooperative Institute for Marine and Atmospheric Studies, University of Miami, and NOAA/Atlantic Oceanographic \\ and Meteorological Laboratory, Hurricane Research Division, Miami, Florida \\ FRANK MARKS \\ NOAA/Atlantic Oceanographic and Meteorological Laboratory, Hurricane Research Division, Miami, Florida \\ Jun A. ZHANG \\ Cooperative Institute for Marine and Atmospheric Studies, University of Miami, and NOAA/Atlantic Oceanographic \\ and Meteorological Laboratory, Hurricane Research Division, Miami, Florida
}

(Manuscript received 23 August 2019, in final form 5 March 2020)

\begin{abstract}
The FV3GFS is the current operational Global Forecast System (GFS) at the National Centers for Environmental Prediction (NCEP), which combines a finite-volume cubed sphere dynamical core (FV3) and GFS physics. In this study, FV3GFS is used to gain understanding of rapid intensification (RI) of tropical cyclones (TCs) in shear. The analysis demonstrates the importance of TC structure in a complex system like Hurricane Michael, which intensified to a category 5 hurricane over the Gulf of Mexico despite over $20 \mathrm{kt}$ $\left(10 \mathrm{~m} \mathrm{~s}^{-1}\right)$ of vertical wind shear. Michael's RI is examined using a global-nest FV3GFS ensemble with the nest at 3-km resolution. The ensemble shows a range of peak intensities from 77 to $159 \mathrm{kt}\left(40-82 \mathrm{~m} \mathrm{~s}^{-1}\right)$. Precipitation symmetry, vortex tilt, moisture, and other aspects of Michael's evolution are compared through composites of stronger and weaker members. The $850-200-\mathrm{hPa}$ vertical shear is $22 \mathrm{kt}\left(11 \mathrm{~m} \mathrm{~s}^{-1}\right)$ in the mean of both strong and weak members during the early stage. Tilt and moisture are two distinguishing factors between strong and weak members. The relationship between vortex tilt and humidification is complex, and other studies have shown both are important for sheared intensification. Here, it is shown that tilt reduction leads to upshear humidification and is thus a driving factor for intensification. A stronger initial vortex and early evolution of the vortex also appear to be the key to members that are able to resist the sheared environment.
\end{abstract}

\section{Introduction}

Tropical cyclone (TC) intensification in vertical wind shear continues to be one of the most pressing challenges in both the research and operational tropical cyclone forecast communities. While recent studies have

\footnotetext{
Corresponding author: Andrew T. Hazelton, andrew.hazelton@ noaa.gov
}

begun to elucidate some of the factors that can contribute to TC intensification in moderate- to high-shear environments [10-20 kt $\left.\left(5-10 \mathrm{~m} \mathrm{~s}^{-1}\right)\right]$, predicting this intensification continues to be challenging.

The intensity change of TCs in moderate-to-high vertical wind shear is a significant subject in recent analysis and discussion. Early studies of TC formation and intensity change (e.g., Gray 1968) discussed shear as a detriment to TC intensification; however, recent 
studies have highlighted the complicated nature of the TC intensity-shear relationship. Bhatia and Nolan (2013) showed that prediction of initially strong TCs in moderate shear $\left[10-20 \mathrm{kt}\left(5-10 \mathrm{~m} \mathrm{~s}^{-1}\right)\right.$ within the 850 200-hPa layer] produced some of the largest errors in TC intensity forecasts models; thus, studies have attempted to understand the details of TC structure and intensity evolution in such cases. Reasor and Eastin (2012) analyzed the evolution of Hurricane Guillermo (1997) in a sheared environment and showed the importance of the evolution of vortex tilt in the resiliency of the TC to the vertical shear. Zhang and Tao (2013) found that vertical shear increased the uncertainty of TC intensity forecasts. Chen and Gopalakrishnan (2015) examined the rapid intensification of Hurricane Earl (2010) in a sheared environment. They found that upshear convection and the advection of the associated upshear warming over the center was important for forming an upper-level warm core and triggering RI. Rios-Berrios et al. (2016a) studied the rapid intensification of Hurricane Katia (2011) in a sheared environment and found that moistening of the low- to midtroposphere in the right-ofshear region was a key factor that allowed the TC to intensify despite the vertical wind shear. Nguyen et al. (2017) compared TCs Bertha (2014) and Cristobal (2014) and found that low- to midlevel moisture was a key factor in the difference in precipitation symmetry and intensity change between these two sheared TCs.

Several other recent studies have examined the structure of TCs in sheared environments. Ryglicki et al. (2018a) used satellite data to examine atypical rapid intensification of sheared TCs, specifically satellite signatures of periodic convective pulses in these TCs, called "tilted-modulated convective asymmetries" (TCAs). Ryglicki et al. (2018b) expanded on this idea using an idealized model to illustrate how TCAs effect vortex structure and evolution in shear. These studies also discussed how shear due to anticyclones (which tends to be confined to upper levels) was more favorable for development than deep-layer shear. Leighton et al. (2018) used an ensemble of Hurricane Weather Research and Forecasting (HWRF) forecasts to study the rapid intensification of Hurricane Edouard (2014) and found that a key difference between intensifying and nonintensifying members was the propagation of convection into the left-of-shear and upshear regions in the intensifying cases. Rogers et al. (2016) found a similar result regarding the importance of upshear convection in Edouard using airborne radar data. Studies such as Zhang et al. (2013, 2017) have further explored the mechanisms responsible for allowing upshear convection and boundary layer recovery despite shear-induced downdrafts, specifically focusing on the importance of surface fluxes. Miyamoto and Nolan (2018) examined an ensemble of idealized simulations and discussed the importance of strong convection to rapid intensification in a moderate shear environment. Wadler et al. (2018) used Doppler radar data to examine the structure of convective bursts and their relationship with intensity change and found that the greatest differences between intensifying and steady-state TCs were in the upshearleft quadrant. The evolution of TCs in shear continues to be a challenging problem, involving interaction among the vortex and synoptic scales. The relationship between the TC environment, vortex structure, and TC intensity in these cases motivates detailed exploration using a state-of-the-art hurricane model in this unique TC that was in a moderate- to high-shear environment.

Over the last few years, FV3-based hurricane models have begun to be applied in the context of highresolution hurricane prediction. Hazelton et al. (2018a) analyzed a high-resolution $(2 \mathrm{~km})$ version of HFV3 with the Geophysical Fluid Dynamics Laboratory (GFDL) configuration of model dynamics and physics by comparing model forecast TC structure with airborne radar observations. Hazelton et al. (2018b) examined a large set of HFV3 cases from the 2017 Atlantic Hurricane season, demonstrating the track and intensity skill of the model as well as the ability to predict structure changes that lead to RI.

This study will build off and expand on these studies by examining a high-resolution ensemble of HFV3 forecasts. While prior high-resolution forecasts focused on a single deterministic member, this study will employ an ensemble approach, motivated by the desire for future development of a high-quality TC ensemble system. This system is applied to a significant TC from the 2018 Atlantic season, Hurricane Michael, to better understand TC structure and intensity evolution in a moderate- to high-shear environment. In section 2, the model setup is described. Section 3 illustrates the differences between strong and weak members, both in a composite sense and also through detailed examination of two specific members. Finally, conclusions of the study are outlined in section 4 .

\section{Data}

\section{a. Case description}

Hurricane Michael was the strongest TC of the 2018 Atlantic hurricane season. The TC formed over the northwestern Caribbean Sea from a Central American gyre (e.g., Papin et al. 2017) and moved into the Gulf of Mexico (GoM). It was a TC that developed and underwent rapid intensification (RI, a change in maximum wind speed of $30 \mathrm{kt}\left(15 \mathrm{~m} \mathrm{~s}^{-1}\right)$ or more in a $24-\mathrm{h}$ period, Kaplan et al. 2010) in a moderate- to high-shear 
environment. Despite large-scale vertical shear in excess of $20 \mathrm{kt}$, it rapidly intensified into a major hurricane and continued to intensify until it made landfall near Mexico Beach, FL, as a high-end category 4 hurricane with maximum sustained winds of $135 \mathrm{kt}$. The rapid intensification of Michael in the Northeast GoM to just below the threshold of category 5 was extremely rare climatologically. In addition, according to Rappaport et al. (2010), in a study of 1979-2008 GoM landfalls, there were no RI events in the GoM north of $25^{\circ} \mathrm{N}$ and east of $90^{\circ} \mathrm{W}$. In addition, GoM major hurricanes tended to weaken before landfall, according to that study. Michael's rapid intensification was very anomalous from a climatological sense. In addition, the spread in the operational forecast guidance was large, with the Statistical Hurricane Intensity Prediction Scheme (SHIPS) predicting a category-1 hurricane and the HWRF model predicting a category 4 hurricane early in Michael's life cycle. The Tropical Cyclone Report for Hurricane Michael notes that both the official and model intensity forecast errors for Michael were significantly larger than the 5-yr mean (Beven et al. 2019). Thus, it is important to understand the source of forecast uncertainty and the factors that allowed Michael to intensify despite strong vertical shear.

\section{b. Model configuration}

The finite-volume cubed sphere dynamical core (FV3) (Lin and Rood 1997; Lin 1997, 2004) has been chosen as the new core of the NOAA Global Forecast System (GFS). While initially a global model, recent work has begun to use FV3GFS (the FV3 core with GFS physics) for high-resolution prediction of impactful weather such as tropical cyclones and severe convection. In this study, ensemble forecasts based on the high-resolution nested version of FV3GFS (hereafter, HFV3) model system are used to study the structure and intensity change of Michael.

The ensemble simulations for Michael were initialized at 1800 UTC 7 October 2018, 6 hours after the system was officially classified as a TC. The physical parameterizations are similar to those used in the operational FV3GFS run by the National Centers for Environmental Prediction (NCEP). For radiation, the model system uses the Rapid Radiative Transfer Model for Global Climate Models (RRTMG, Iacono et al. 2008). For planetary boundary layer (PBL) physics, the nonlocal Han and Pan (2011) parameterization is used. The convective parameterization is the recently updated scale-aware cumulus parameterization that is operational in both the GFS (Han et al. 2017) and HWRF models. The 6-class single-moment Geophysical Fluid Dynamics Laboratory (GFDL) microphysics is used (Chen and Lin 2013; Zhou et al. 2019), as in the
TABLE 1. Physical parameterizations used in this study.

\begin{tabular}{lll}
\hline \hline Physical process & \multicolumn{1}{c}{ Scheme } & \multicolumn{1}{c}{ Reference } \\
\hline Convection & Scale-aware SAS & Han et al. (2017) \\
Microphysics & GFDL & Chen and Lin (2013) \\
PBL & GFS & Han and Pan (2011) \\
Radiation & RRTMG & Iacono et al. (2008) \\
\hline
\end{tabular}

operational GFS. This scheme is similar to the 6-class scheme of Lin et al. (1983). The physical parameterizations are summarized in Table 1.

For this study, a high-resolution 3-km nested grid covering most of the North Atlantic is embedded in a $13-\mathrm{km}$ uniform global grid. There is two-way feedback between the nested grid and the global grid (Harris and Lin 2013). Both the global and nested grids use 63 vertical levels. A similar setup (although with a slightly different nested grid) was used in Hazelton et al. (2018b) in a large set of hindcasts from the 2017 Atlantic hurricane season, and demonstrated skill in forecasting TC track, intensity, and structure. The horizontal resolution of $\sim 3 \mathrm{~km}$ should be able to capture most of the innercore structure, although the smallest inner core features (such as small-scale eyewall asymmetries) may not be resolved. Figure 1 shows the global grid layout in both a cube and "unwrapped" perspective and also highlights the region covered by the Atlantic nest.

\section{c. Ensemble setup}

The current version of FV3GFS does not have a separate data assimilation system, but rather uses the initial conditions from the GFS analyses; ${ }^{1}$ thus, in order to construct an ensemble system, 40 members are randomly selected from the Global Ensemble Forecast System (GEFS) analyses. These 40 members come from an 80-member ensemble Kalman filter (EnKF) data assimilation system (Zhou et al. 2017). A deterministic HFV3 forecast is also included at the same model resolution, initialized with the full-resolution operational GFS analysis. This makes a total of 41 high-resolution forecast members for this case. The members were "cold-started" from the GEFS analyses, with no artificial vortex modification. The members were run out to $120 \mathrm{~h}$, covering a period including the track of Michael across the GoM to landfall along the northern Gulf Coast, and extending inland over the eastern United States after landfall. The initial sea surface temperature

\footnotetext{
${ }^{1}$ The FV3GFS became operational on 12 June 2019 (i.e., GFS). Before that date, the GFS was referred to as the Global Spectral Model operated in NCEP. The GFS analysis was the highresolution analysis based on operational GFS on that date.
} 
a)

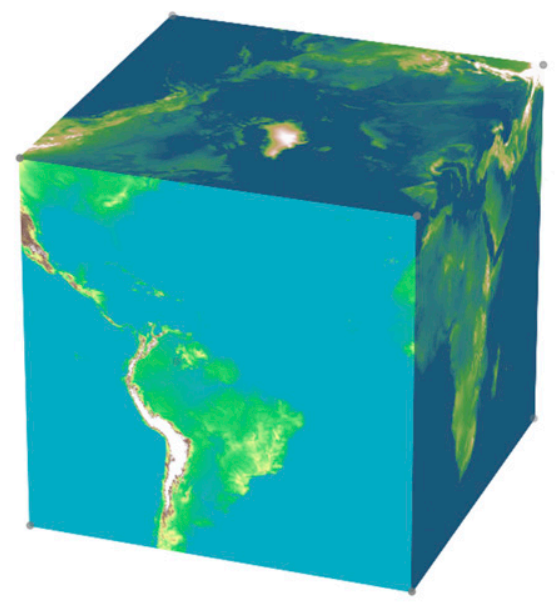

b)

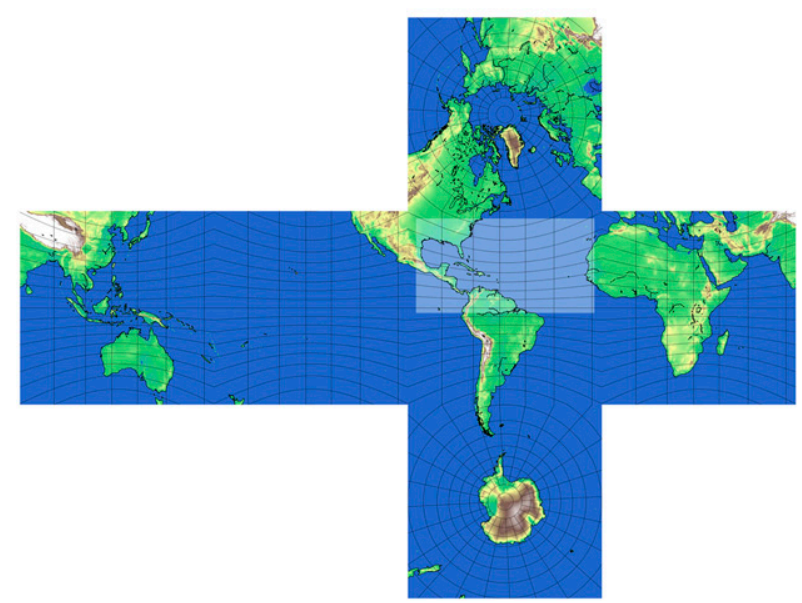

FIG. 1. (a) Terrain from the 6 global tiles of the FV3 dynamical core used in this study, represented as a cube. (b) As in (a), but "unwrapped" and with light blue shading highlighting the highresolution Atlantic nest.

(SST) from the GEFS fields is kept constant throughout the simulation, as ocean coupling is a capability still in development. The SST along the path of Michael were $1^{\circ}-2^{\circ} \mathrm{C}$ higher than average (not shown), and the relatively fast movement of the TC meant that ocean cooling was likely not a substantial hindrance to intensification.

\section{Results}

\section{a. Basic ensemble statistics}

\section{1) TRACK AND INTENSITY}

Figure 2 shows the tracks of all 40 members from the ensemble forecast and the deterministic forecast. The

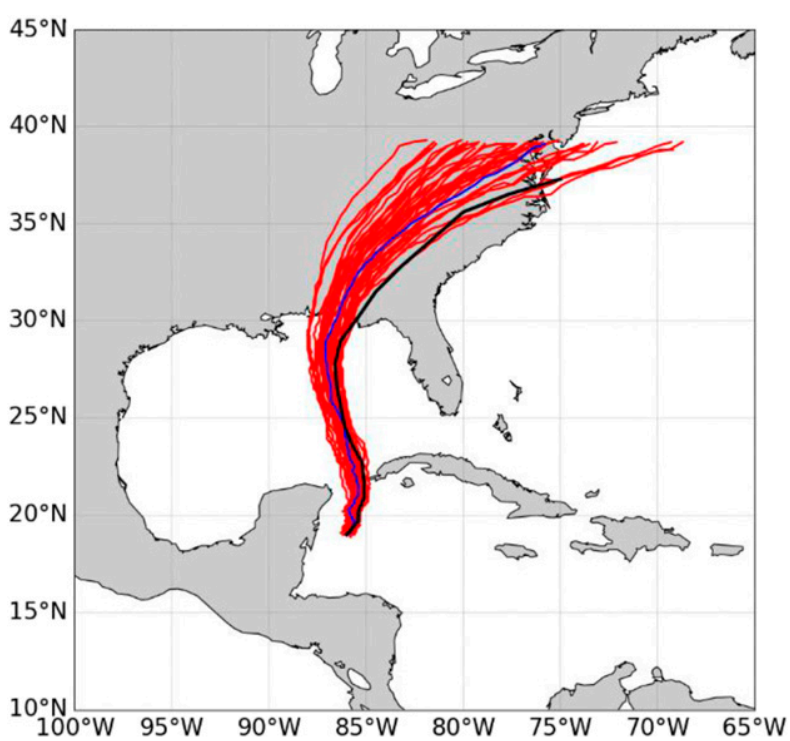

FIG. 2. The 5-day forecast tracks of all $40 \mathrm{HFV} 3$ ensemble members (red) and the deterministic HFV3 forecast for Hurricane Michael (blue) initialized at 1800 UTC 7 Oct 2018. The observed track (best track) is shown in black.

tracks are generally close to the observed track of Michael, although there is a left bias with all members falling along or left of the observed. The tight clustering with a relatively consistent bias may be indicative of under dispersion in track forecasts due to the initialization from GEFS (e.g., Zhou et al. 2017; Buizza et al. 2000), which was similarly underdispersive in track (not shown). Figure 3 shows the intensity forecasts from all 41 forecasts. In contrast to the track forecasts, there was a large spread in intensity forecasts, with peak wind speed ranging from 77 to $159 \mathrm{kt}\left(39-82 \mathrm{~m} \mathrm{~s}^{-1}\right)$. Previous work has shown that shear decreases the predictability of TC intensity (e.g., Zhang and Tao 2013), so this large intensity spread is not surprising. In general, most members slightly underpredicted the intensity; however, many did show quick deepening before landfall, and about $20 \%-$ $25 \%$ did reach or exceed the observed peak intensity.

Rapid intensification (RI) is defined as an increase in maximum sustained winds of $30 \mathrm{kt}\left(15 \mathrm{~m} \mathrm{~s}^{-1}\right.$ in $24 \mathrm{~h}$ (Kaplan et al. 2010). Two periods of intensification are examined: hours $12-36$ and $36-60$. The structure at the start of these periods will be a focus later. The observed TC fell just short of the RI threshold for the first period, with an increase of $25 \mathrm{kt}\left(13 \mathrm{~m} \mathrm{~s}^{-1}\right)$ but met it for the second, with an increase of $35 \mathrm{kt}\left(18 \mathrm{~m} \mathrm{~s}^{-1}\right)$. Of the ensemble members, $8 / 41$ met the RI threshold during the first period, while 20/41 met the threshold during the second period. This provides further evidence that the ensemble set reasonably reflected the overall intensity evolution of Michael. 
a)

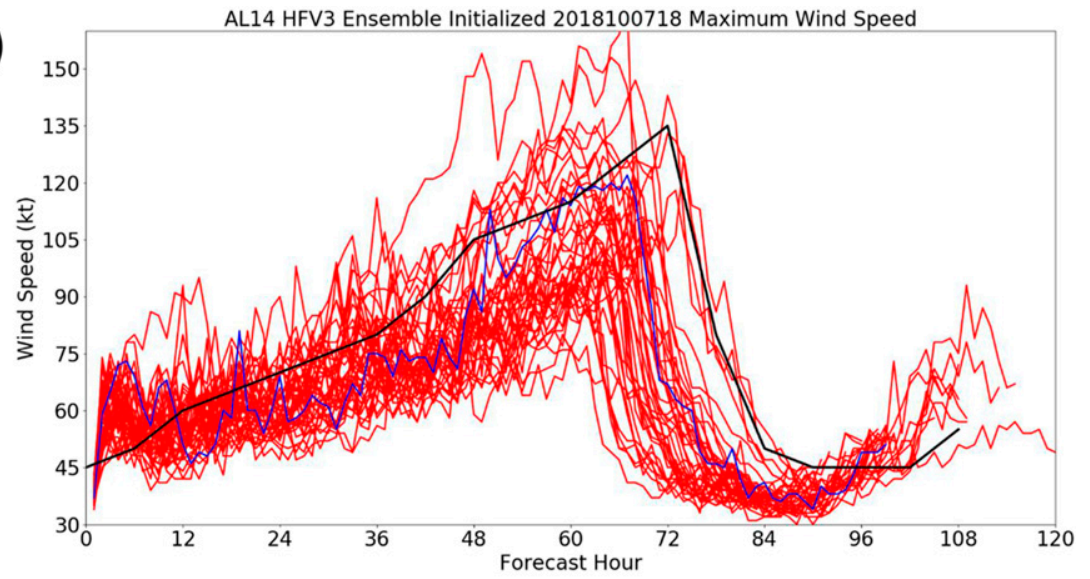

b)

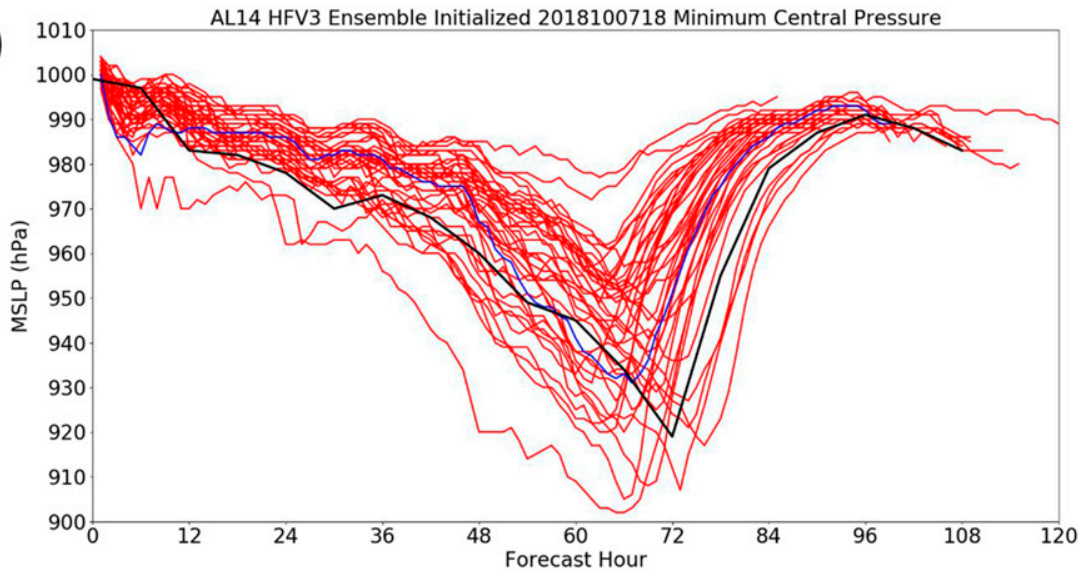

FIG. 3. (a) Maximum wind speed and (b) minimum central pressure of all $40 \mathrm{HFV} 3$ ensemble members (red) and the deterministic HFV3 forecast for Hurricane Michael (blue) initialized at 1800 UTC 7 Oct 2018. The observed track (best track) wind speed and pressure is shown in black.

\section{2) WIND RADII}

To examine the ensemble spread in more detail, the wind radii were also calculated. Figure 4 shows box plots of the forecast and observed radius of maximum wind (RMW) and radius of 34-kt wind (R34). While analyzed wind radii can have large errors in some cases, analyses from Michael were likely more accurate due to a plethora of aircraft observations (e.g., Cangialosi and Landsea 2016), with four NOAA Hurricane Hunter P-3 flights and eight Air Force C-130 Hurricane Hunter flights providing near-constant sampling of the storm's inner and outer wind radii from genesis through landfall.

The RMW (Fig. 4a) has a fairly large spread early in the forecast, as a small inner core developed within a broader, gyre-like circulation (e.g., Papin et al. 2017); however, after the first $\sim 24 \mathrm{~h}$, the variability decreases, and the observed RMW is close to the median of the ensemble envelope. Interestingly, the RMW remains relatively constant after hour 36 in both the model and observations. The intensity change at various periods will be examined later in the paper. The radius of 34-kt winds (R34, Fig. 4b) is generally too large early in the forecast period. However, it is close to the observed after hour 48, with a marked increase in R34 (as well as RMW) after landfall as extratropical transition occurred.

\section{b. Synoptic overview}

First, the synoptic upper-level pattern surrounding Michael is examined, to help understand some of the large-scale factors affecting Michael's intensity change and to begin to explore differences between the members. Figure 5 shows the $850-200-\mathrm{hPa}$ shear and 200-hPa streamlines from a representative ensemble member, every $18 \mathrm{~h}$ from 6 to $60 \mathrm{~h}$. Initially, the TC was sheared by upper-level flow around an anticyclone to its southwest. Shear from anticyclones has been shown to be shallow and less hostile to TC development than deep-layer 
a)

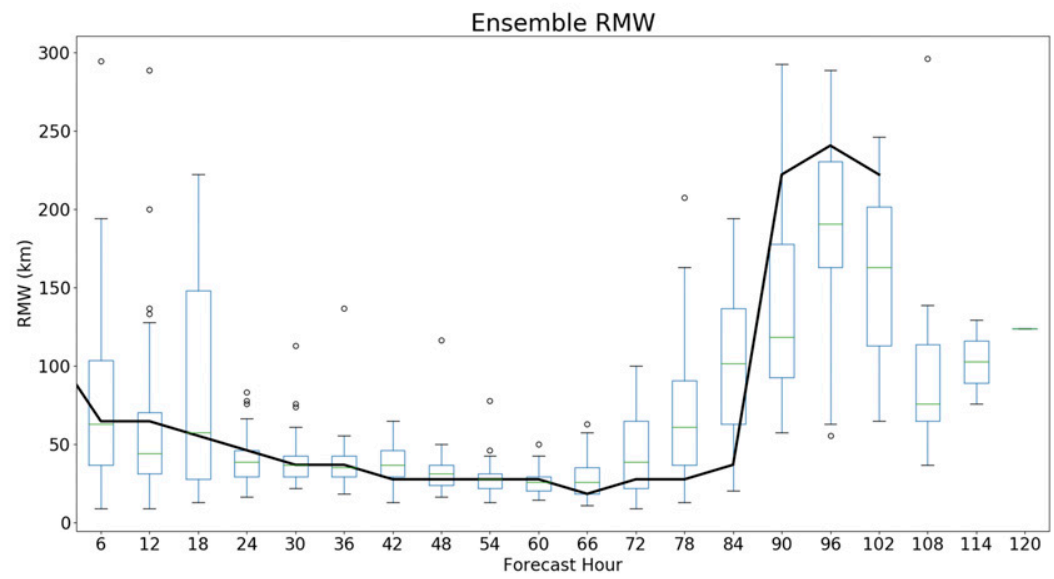

b)

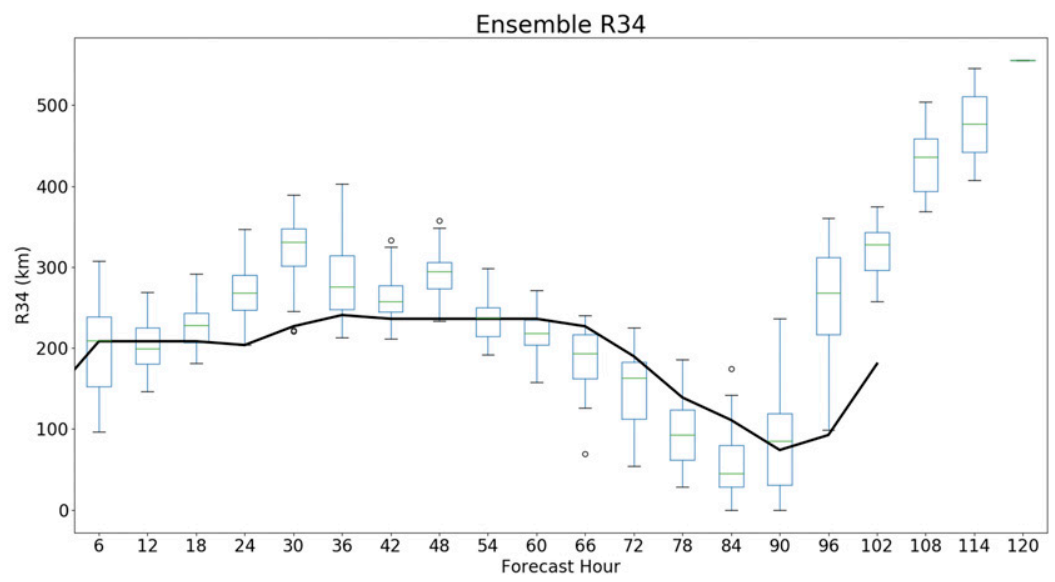

FIG. 4. (a) Boxplot of the radius of maximum wind of all 41 HFV3 ensemble members initialized at 1800 UTC 7 Oct 2018. The open circles represent outlier members. The observed track (best track) radius of maximum wind is shown in black. (b) As in (a), but for radius of 34-kt $\left(17 \mathrm{~m} \mathrm{~s}^{-1}\right)$ wind.

shear from troughs (e.g., Ryglicki et al. 2018a). In addition, there was a large area of upper-level diffluence to the northeast of the TC, with an outflow jet enhanced by an upper-level low east of the Bahamas. This provided an environment favorable for convection to help the TC resist the shear. Later on, the outflow jet to the east of the TC continued, and outflow was also enhanced north of the TC due to an approaching upper-level trough. However, outflow was restricted on the west side of the TC due to the approaching trough.

To explore whether differences in the TC location relative to the trough may have contributed to the intensity differences, Fig. 6 shows the ensemble tracks, colored by the lifetime minimum pressure of each member. The weakest members $(970-980 \mathrm{hPa})$ do appear on the west edge of the ensemble suite. However, 4-5 of the weaker members $(950-970 \mathrm{hPa})$ also appear in a similar location to many strong members. So, the location of the TC relative to the trough may have played some role but was likely not the sole factor contributing to intensity change. To further illustrate this, the large-scale vertical wind shear is also calculated. The shear is defined, using a methodology similar to the SHIPS model (e.g., DeMaria and Kaplan 1994), as the 850-200-hPa shear in an annulus of $200-800 \mathrm{~km}$ from the TC center. Figure 7 shows the evolution of minimum central pressure and the simultaneous changes in the shear. The large-scale shear was in the moderate to high range for the first $48 \mathrm{~h}$ of the forecasts in both the ensembles and observations, as defined by SHIPS. Despite this shear, the TC intensified to $950 \mathrm{hPa}$ in these $48 \mathrm{~h}$. Bhatia and Nolan (2013) noted that strong TCs [>70 kt $\left(36 \mathrm{~m} \mathrm{~s}^{-1}\right)$ intensity] in moderate shear [10-20 kt $\left.\left(5-10 \mathrm{~m} \mathrm{~s}^{-1}\right)\right]$ presented one of the biggest challenges to model forecasts of TC intensity, which is reflected in the large intensity spread seen here. The intensification was captured by a few, although not the majority, of the members. After hour 48, in both the model members 
a) $006 \mathrm{~h}$ Forecast $850-200 \mathrm{hPa}$ Shear (kt, Shaded)

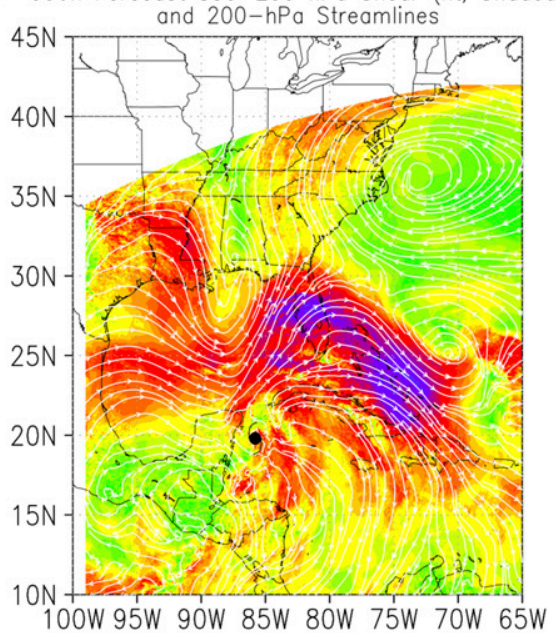

c)

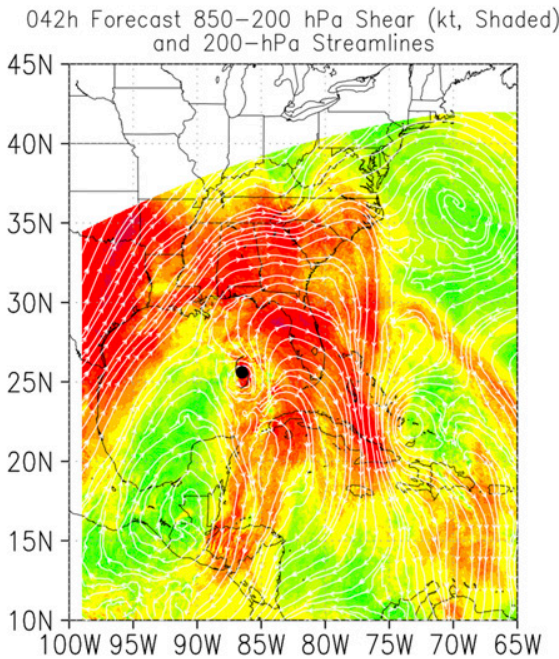

b) $024 \mathrm{~h}$ Forecast $850-200 \mathrm{hPa}$ Shear (kt, Shaded)

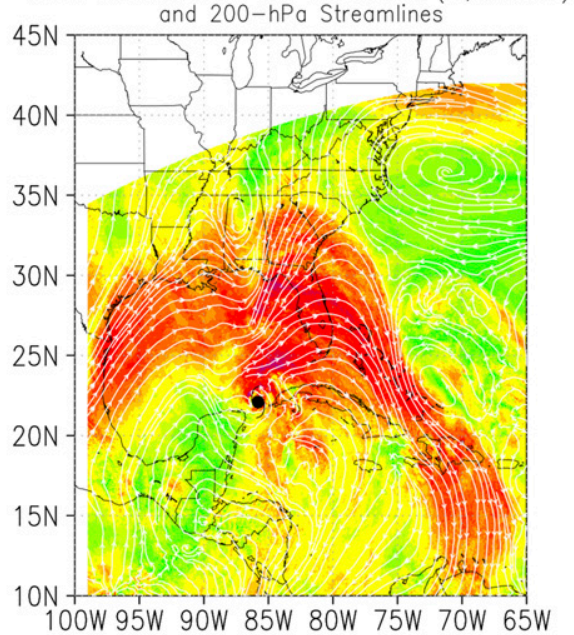

d)

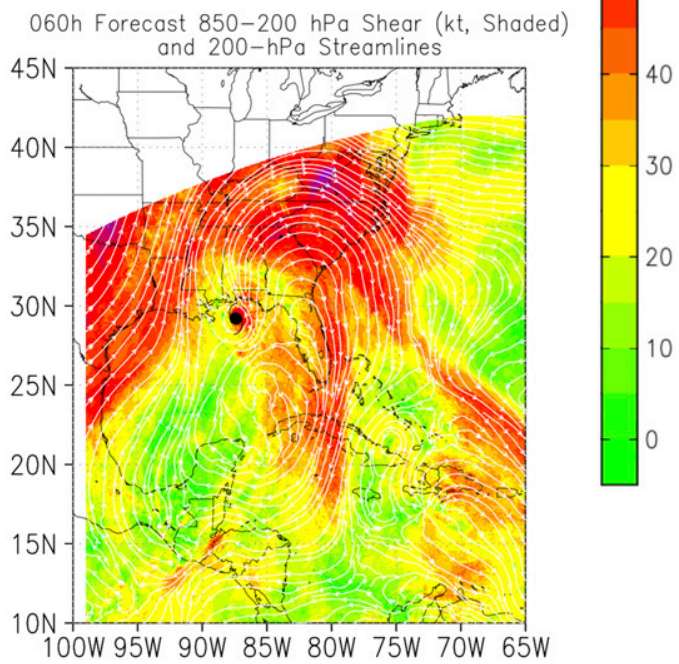

FIG. 5. (a) The 850-200-hPa shear (shaded) and 200-hPa streamlines at $6 \mathrm{~h}$ from one of the ensemble members.

(b) As in (a), but at $24 \mathrm{~h}$. (c) As in (a), but at $42 \mathrm{~h}$. (d) As in (b), but at $60 \mathrm{~h}$.

and observations, the shear decreased and the intensification continued at a faster pace, although there was a slight spread in shear, which seemed to be associated with proximity to the trough. The overall consistency between the model and observed shear, as well as the large intensity spread despite relatively small shear spread, gives confidence that changes in TC intensity are related to other factors besides just differences in largescale flow.

\section{c. Structure metrics}

Some recent studies examining various sheared TCs in both observational and model frameworks (e.g., Zawislak et al. 2016; Munsell et al. 2017; Nguyen et al. 2017; Shimada et al. 2017; Rios-Berrios et al. 2018; Tao and Zhang 2019) have shown that two key processes in intensification of TCs in sheared environments are symmetrization of the vortex and reduction of the vertical tilt. In this study, we expand on these ideas by calculating specific structure metrics to examine these two processes in the simulations, to quantitatively examine whether vortex dynamical and/or thermodynamic structure were important in the evolution of Michael. The metrics evaluated were as follows.

Tilt is defined as the distance between the 850 - and $500-\mathrm{hPa}$ centers (to represent the low and midlevel centers, calculated using the geopotential centroid method of Alaka et al. 2019):

$$
\text { Tilt }=\sqrt{\left(x_{850}-x_{500}\right)^{2}+\left(y_{850}-y_{500}\right)^{2}},
$$




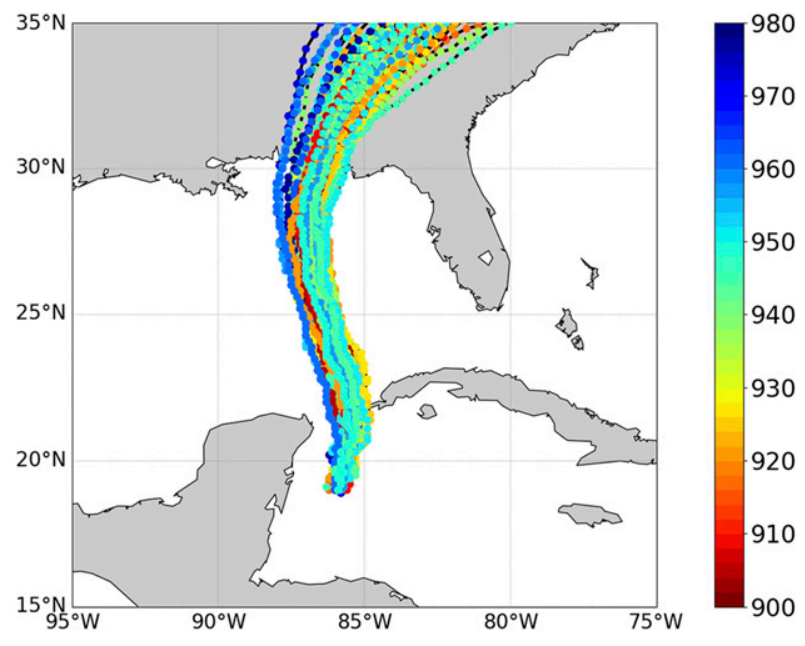

FIG. 6. Tracks of all ensemble members, colored by the lowest minimum central pressure $(\mathrm{hPa})$ of each member during the entire forecast.

where $x_{850} / y_{850}$ and $x_{500} / y_{500}$ are the center locations at each height.

Symmetry is based on 4-km reflectivity (midlevel, but below the melting level) and is defined as the ratio of the wavenumber- 0 field to the total field. This is similar to a metric based on vorticity in Miyamoto and Takemi (2013):

$$
S=\frac{W_{0}}{W_{0}+\sum W_{n}}
$$

where $W_{0}$ is the wavenumber- 0 component, and is compared with the sum of the higher-wavenumber terms $\left(W_{n}\right)$ from a Fourier decomposition. The wavenumbers are calculated in the eyewall region, defined as $R^{*}=0.75 \mathrm{RMW}_{850}$ to $R^{*}=1.25 \mathrm{RMW}_{850}$, where $\mathrm{RMW}_{850}$ is the radius of maximum winds at $850 \mathrm{hPa}$. Two measures of symmetry are discussed below: $S_{\text {all }}$, which calculates the ratio of the symmetric field to the total field including all asymmetric components, and $S_{1}$, which calculates the ratio of the symmetric field to the combination of the symmetric and wavenumber-1 field. This is useful in the context of this study because the precipitation structure of sheared TCs often exhibits a wavenumber-1 asymmetry (e.g., Chen et al. 2006; Reasor et al. 2013).

Closure is also based on 4-km reflectivity and measures the percentage of the eyewall, again defined as $R^{*}=0.75 \mathrm{RMW}_{850}$ to $R^{*}=1.25 \mathrm{RMW}_{850}$, where there is a radial band of at least two grid points at a given azimuth (at $5^{\circ}$ azimuthal resolution) that has reflectivity of at least $20 \mathrm{~dB} Z$. This metric essentially measures how much of the TC eyewall region consists of at least moderate precipitation. This metric is similar to the

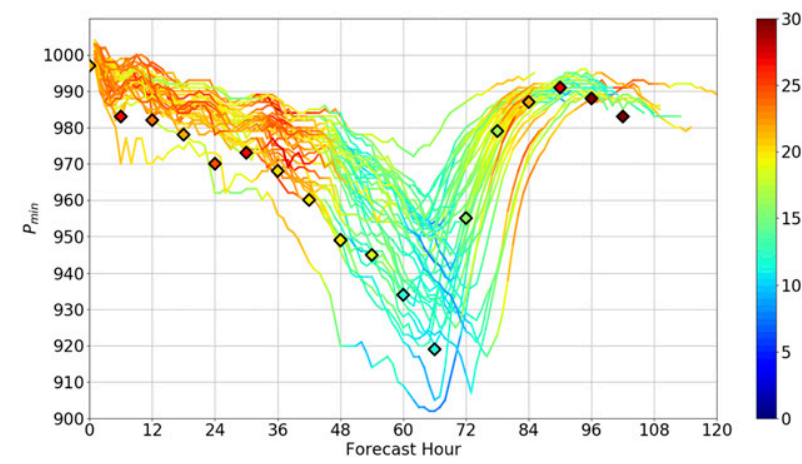

FIG. 7. Minimum central pressure (hPa) of the 41 Michael forecasts used in this study. The lines are shaded by the 850 200-hPa vertical shear magnitude (kt, $1 \mathrm{kt}=0.5144 \mathrm{~m} \mathrm{~s}^{-1}$ ). The observed pressure from best track and the observed shear from SHIPS (every $6 \mathrm{~h}$ ) is shown by the large diamonds.

closure metric defined in a study of Hurricane Isabel (2003) by Matyas et al. (2018), but is more confined to the eyewall region $\left(R^{*}=0.75-1.25\right)$ than the metric in that study:

$$
\text { Closure }=\frac{\sum_{0^{\circ}}^{360^{\circ}} \alpha \quad(\text { if } \mathrm{dB} Z \geq 20)}{\sum_{0^{\circ}}^{360^{\circ}} \alpha} .
$$

The metrics were calculated from the model data and also were compared (where applicable) with the observed data from the radar onboard the NOAA P-3, which flew four times into Hurricane Michael. The structure metric time series (Fig. 8) show that, unsurprisingly, symmetry increases and tilt decreases as vertical shear decreases around hours 48-60; however, there are also some differences earlier in the forecasts. In general, members that intensified more quickly had greater symmetry and smaller vortex tilt even when the shear was strong early in the forecast period. There was some relationship between the ensemble peak intensity and the initial tilt, but it was not statistically significant $(r=0.20, p=0.22)$. This implies that the early vortex structure evolution after initialization, rather than the initial tilt, was key to the intensification of Michael in shear. The structure changes and differences are further quantified in the next section.

\section{d. Differences between strong and weak members for two intensification periods}

To explore the environmental and structural factors that allowed Michael to rapidly intensify despite shear that was marginal to hostile based on traditional shear metrics (e.g., DeMaria and Kaplan 1994), differences between the strong and weak members were explored. 
a)

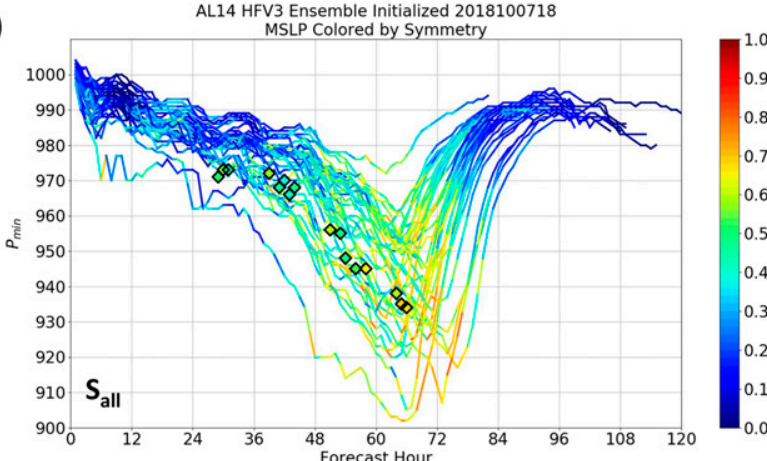

c)

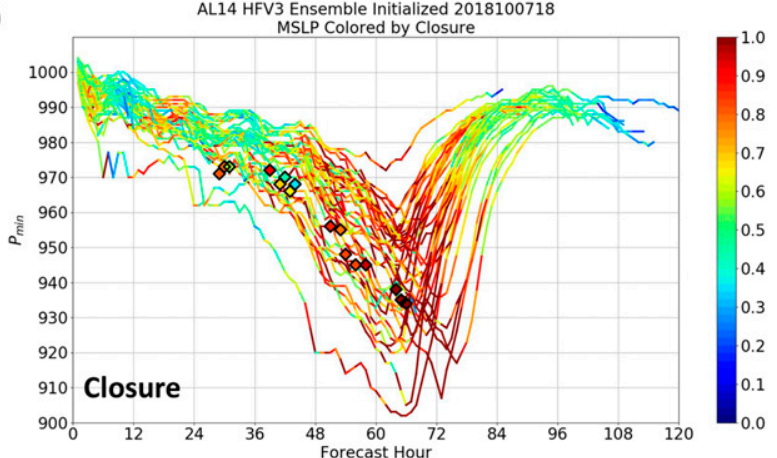

b)

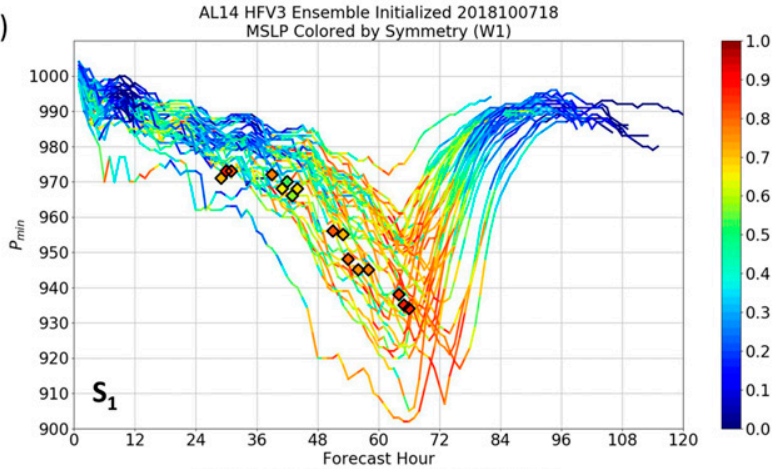

d)

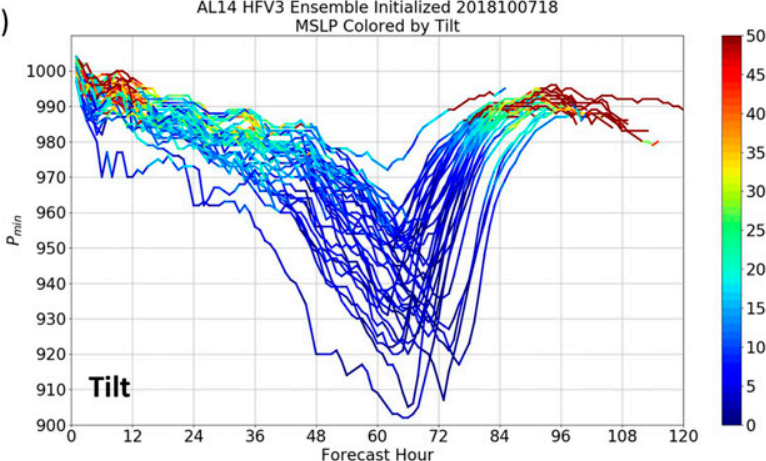

FIG. 8. (a) Minimum central pressure (hPa) of the 41 Michael forecasts used in this study. The lines are shaded by the symmetric metric $S_{\text {all }}$. The observed pressure and symmetry (from NOAA P-3 flights) are shown in the diamonds. (b) As in (a), but shaded by the wavenumber-1 symmetry metric $S_{1}$. (c) As in (a), but shaded by the closure metric. (d) As in (a), but shaded by the vortex tilt.

The members were defined based on the minimum pressure at hour 60 . The deterministic forecast also fell within the "strong" set. Both composite differences and individual differences between the sets, both early and toward the middle of the forecasts (hours 12 and 36) are examined next.

\section{1) COMPOSITES OF STRONG AND WEAK MEMBERS}

As mentioned above, there were no major differences in the large-scale shear evident in the time series. Spatial composite comparisons of shear (not shown) were also very similar in the strong and weak sets. While it is possible that some of the shear experienced by the TC occurred outside this $850-200-\mathrm{hPa}$ layer, deep-layer soundings averaged over the large-scale environment showed similar environmental wind profiles for both strong and weak members (not shown). Thus, the differences in large-scale shear did not appear to be a major distinguishing factor in the early intensification period.

The traditional large-scale shear metrics may have overestimated the shear for Michael, which was located on the edge of a shear gradient (see Fig. 5). Also, as noted in Ryglicki et al. (2019), sometimes convectively induced outflow can "push back" against the large-scale shear and insulate the core. We wanted to explore whether this led to reduced "local" shear for the strong members. For both sets, "local" shear was defined by the shear in $r=0-200 \mathrm{~km}$ annulus. Table 2 shows the mean values for the strong and weak members at hours 12 and 36. The "local" shear was indeed at least $4-5 \mathrm{kt}$ lower than the large-scale shear. However, the differences between strong and weak members in local shear were insignificant at both forecast hours. This seems to imply that other synoptic or structural variables were more important to the evolution of Michael.

One synoptic variable that has been shown to be important in some high-shear RI cases is low- to midtropospheric moisture (e.g., Rios-Berrios et al. 2016a,b; Zawislak et al. 2016; Nguyen et al. 2017; Leighton et al. 2018). Given that the local and large-scale shear differences between members were not huge, this was seen as a potential large-scale difference in Michael that was worthy of further exploration. Figures 9 and 10 show composites of precipitable water and $500-\mathrm{hPa}$ relative humidity for the strong and weak members, as well as the difference composites. In this composite, the horizontal coordinates are normalized by the $850-\mathrm{hPa}$ RMW to prevent artifacts from TCs of different size.

At hour 12 , prior to early intensification, both composites show an area of midlevel dry air near the core of the TC on the west/upshear side. However, the difference plot shows that the strong members tend to be 
TABLE 2. Mean values of structure metrics tilt (km), symmetry, and closure, as well as basic metrics minimum central pressure (hPa), RMW (km), and shear (kt, $1 \mathrm{kt}=0.5144 \mathrm{~m} \mathrm{~s}^{-1}$ ) at hours 12 and 36 for the strong and weak members (defined based on intensity at hour 60). The statistical significance of the difference between the groups is shown in the bottom row, and significant relationships are listed in italics.

\begin{tabular}{lcccccccc}
\hline \hline & Pmin $(\mathrm{hPa})$ & RMW $(\mathrm{km})$ & Shear $(\mathrm{kt})$ & Tilt $(\mathrm{km})$ & $S_{\text {all }}$ & $S_{1}$ & Closure & Local shear \\
\hline Hour 12 & & & & & & & & \\
$\quad$ Mean strong & 986.9 & 65.3 & 21.8 & 27.0 & 0.19 & 0.31 & 0.54 \\
$\quad$ Mean weak & 991.7 & 74.1 & 22.5 & 33.5 & 0.17 & 0.27 & 0.49 & 16.8 \\
$\quad P$ value & 0.001 & 0.11 & 0.14 & 0.13 & 0.34 & 0.27 & 0.13 & 0.14 \\
Hour 36 & & & & & & & \\
$\quad$ Mean strong & 973.2 & 44.7 & 23.1 & 12.4 & 0.26 & 0.37 & 0.53 \\
$\quad$ Mean weak & 981.8 & 54.1 & 24.9 & 21.9 & 0.15 & 0.22 & 0.47 \\
$\quad P$ value & 0.000003 & 0.007 & 0.06 & 0.000007 & 0.001 & 0.0005 & 0.05 & 19.6 \\
\end{tabular}

moister in this region as well as in the north/left-ofshear quadrant. The differences are even more pronounced when looking at the precipitable water. There is an area of dry low- to midlevel air on the west side, but it is more pronounced in the weak members, and the difference plots show that the strong members have much higher moisture in this area.

At hour 36, the strong composites again show much greater low- and midlevel moisture than the weak composites. The difference composites highlight two key regions that are particularly different between the sets. Close to the storm center $\left(R^{*}=2-4\right)$, there is a region of higher moisture wrapping from the southeast side/downshear-right to the northwest side/upshear-left. This is consistent with the idea of wrapping of convection in intensifying cases that was discussed in Leighton et al. (2018). However, an even greater difference exists in the large-scale moisture at a larger distance $\left(R^{*}=\right.$ 5-10) from the TC center. The intensifying TCs have greater moisture in the upshear regions, wrapping around the south side of the storm. This implies that despite similar shear in the two cases, the moisture content in the upshear region was critical for allowing the TC to build a core and intensify despite the shear (e.g., Rogers et al. 2016). To confirm whether there was greater precipitation wrapping into the upshear region in the strong cases, Figs. 11 and 12 show the composite 4-km simulated reflectivity for the strong and weak members, as well as the differences between the member composites.

At hour 12, the composites appear fairly similar at first glance, a very asymmetric precipitation distribution with precipitation focused on the east/downshear side. This is due to the typical shear-relative precipitation pattern that has been well documented (e.g., Corbosiero and Molinari 2002; DeHart et al. 2014). However, there are some subtle differences between the composites, which are particularly highlighted in the difference plot (Fig. 11c). The strong members (from hours 12-36) have more precipitation in the outer core $\left(R^{*}=4-6\right)$ region left-of-shear (on the north side), and also more precipitation in the inner-core region right-of-shear. However, the differences upshear are fairly small at this lead time.

At hour 36, there are again some similarities between the composites, especially the tendency for precipitation on the east/downshear side. This asymmetry was also seen in the observed TC, as shown later. However, there are some differences that stand out, especially in the difference plot (Fig. 12c). The composite for the strong cases features a ring of $20 \mathrm{dBZ}$ reflectivity wrapping around the west/upshear side of the core. In addition, precipitation is stronger in the northeast quadrant/downshear-left for the strong members, but in the southeast quadrant/downshearright for the weak members. The precipitation was able to form downshear-right but wrap upshear to the west side of the storm in the strong members, but remained more confined to the downshear region in the weak members. This will be quantified in the examination of structure metrics in weak/strong cases in the next section.

The impact of upshear humidity on TC intensification has been documented in other cases, as noted above. However, this ensemble set provides a unique opportunity to examine this evolution over a wide intensity range. To further examine the role of moisture and how this changed over time, time series of precipitable water and 500-hPa relative humidity from hours 0 to 60 were created for the means of the strong and weak members. These are shown in Fig. 13. As will be seen in a cross section later, the biggest differences between the strong and weak members seemed to be in the mid- to upper levels, which is why $500 \mathrm{hPa}$ was chosen, but the precipitable water also gives an idea of the overall moisture environment near and around the TC. Time series were shown of the relative humidity and precipitable water averaged over a $200-600 \mathrm{~km}$ annulus around the TC, and were calculated for both the western/upshear and northeastern/downshear-left quadrants of the TC. 
a)

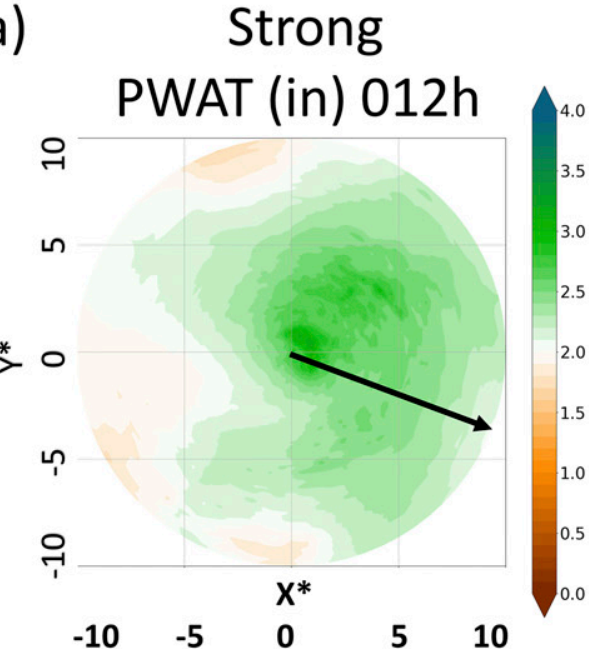

c)

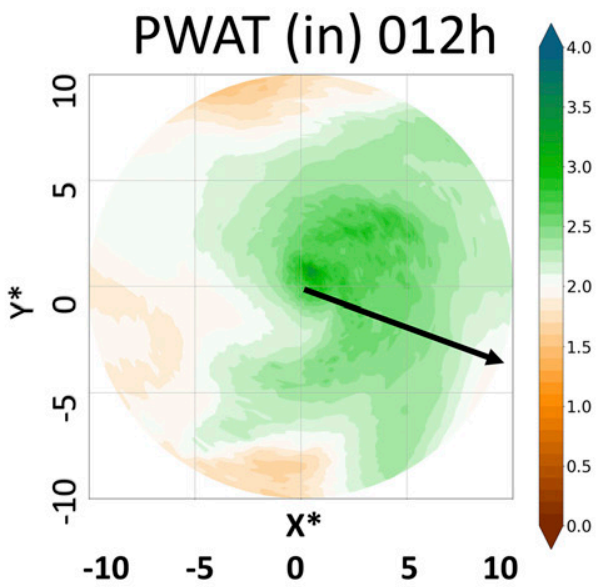

e) Strong-Weak

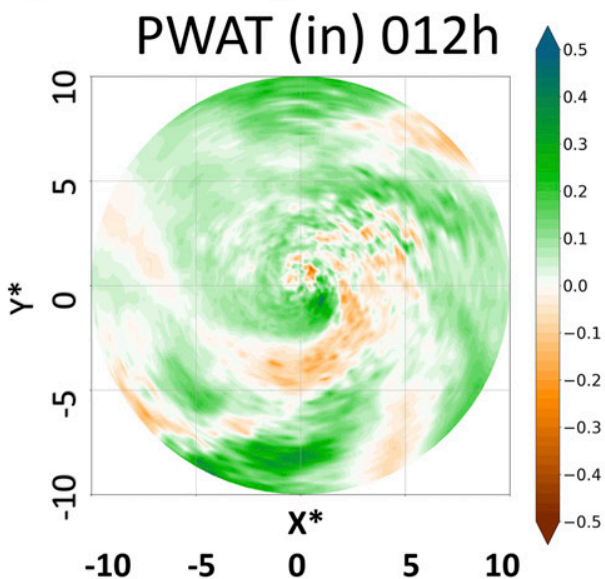

b) Strong

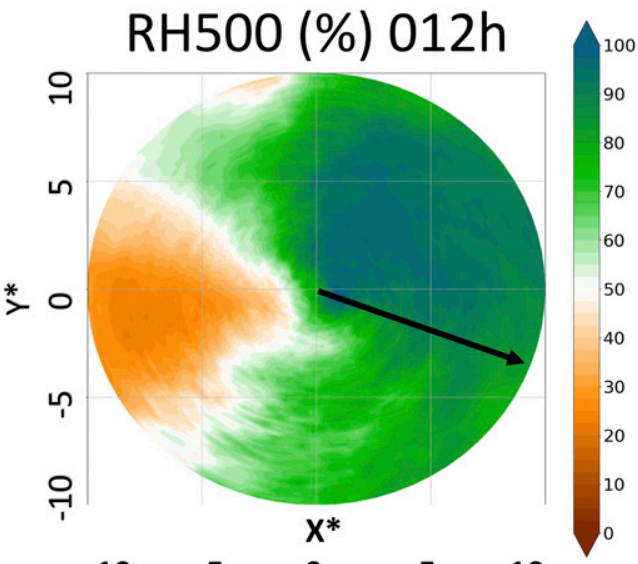

d)
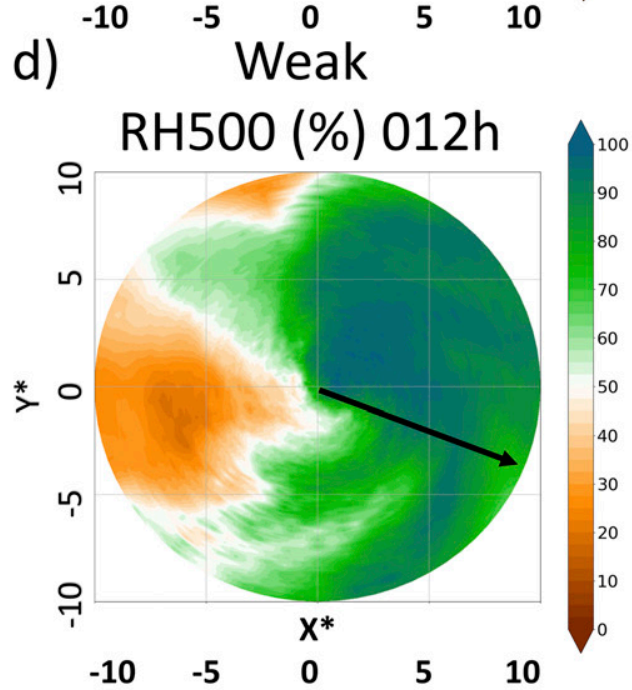

f) Strong-Weak

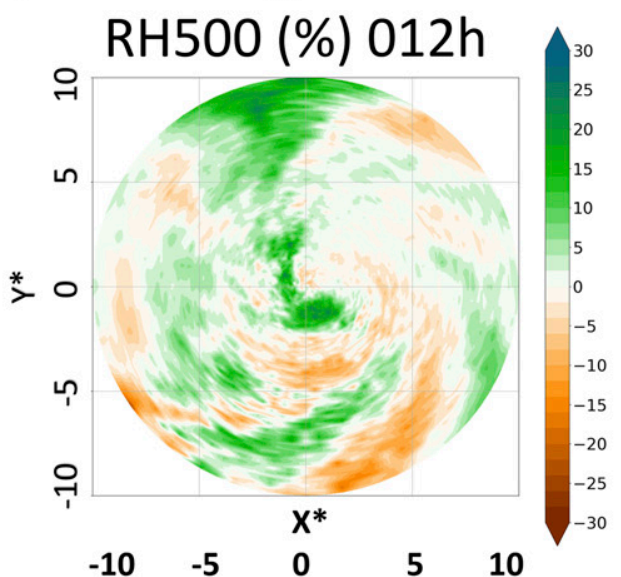

FIG. 9. (a) Composite precipitable water $(\mathrm{mm})$ at $12 \mathrm{~h}$ for the 20 "strong" members based on intensity at $60 \mathrm{~h}$. The coordinate system is normalized by the $850-\mathrm{hPa}$ radius of maximum wind (RMW). The mean shear vector from the strong members is shown in the black arrow. (b) As in (a), but for the 500-hPa relative humidity. (c) As in (a), but for "weak" members. (d) As in (b), but for "weak members. (e) The difference in precipitable water between the strong and weak members. (f) The difference in relative humidity between the strong and weak members. 
a) Strong

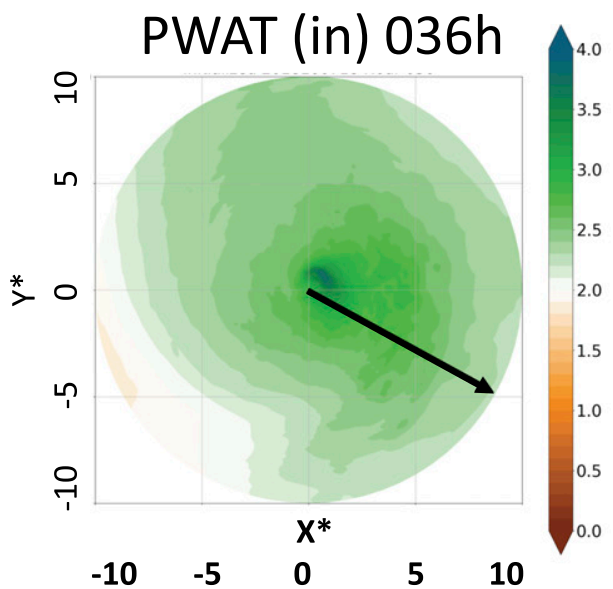

c)

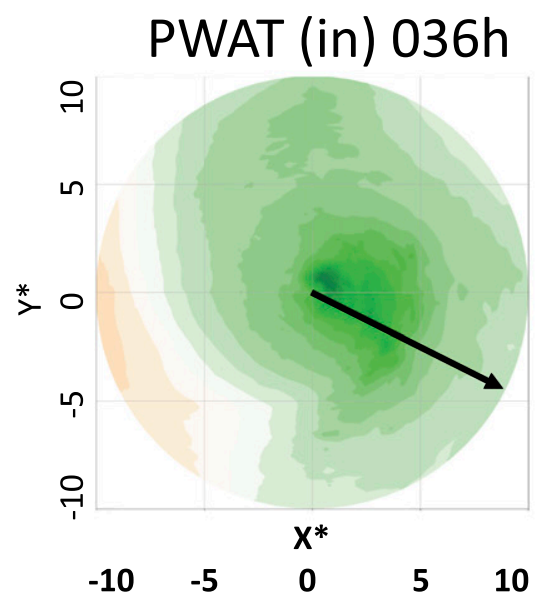

e) Strong-Weak
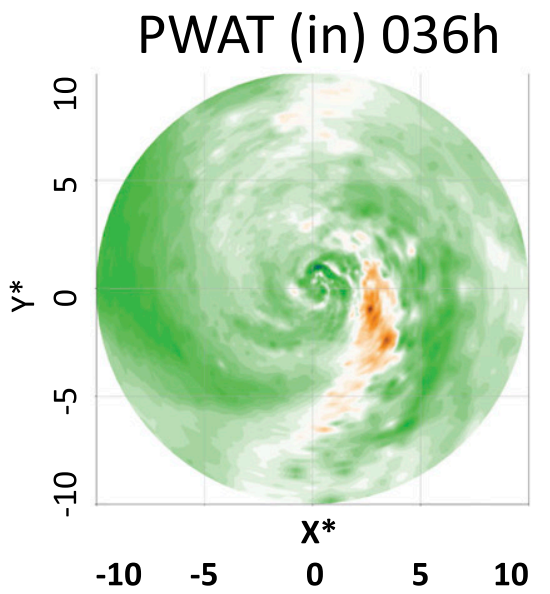

b)

Strong
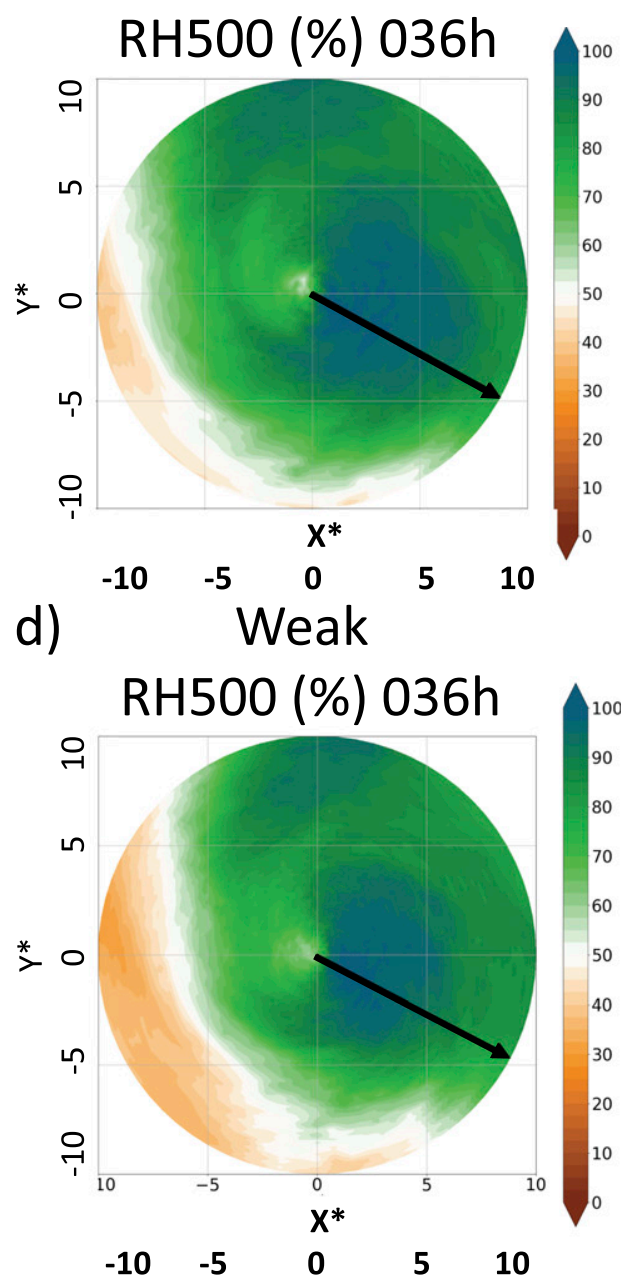

f) Strong-Weak
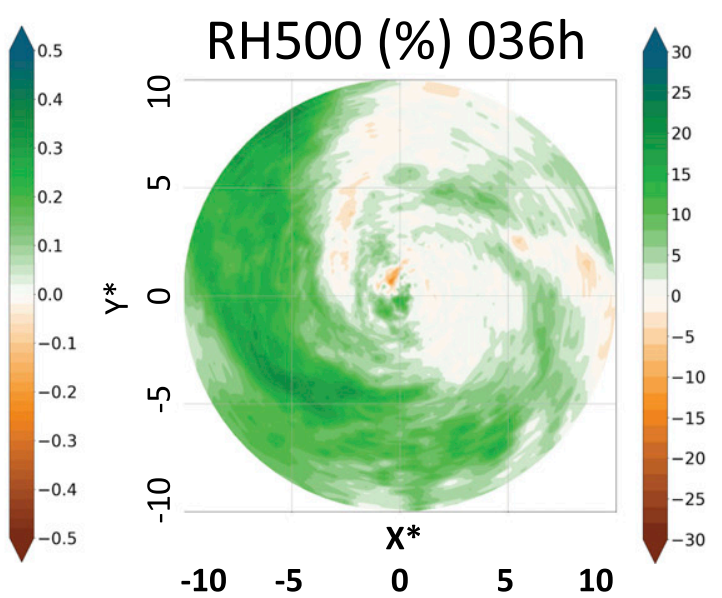

FIG. 10. As in Fig. 9, but valid at $36 \mathrm{~h}$. 

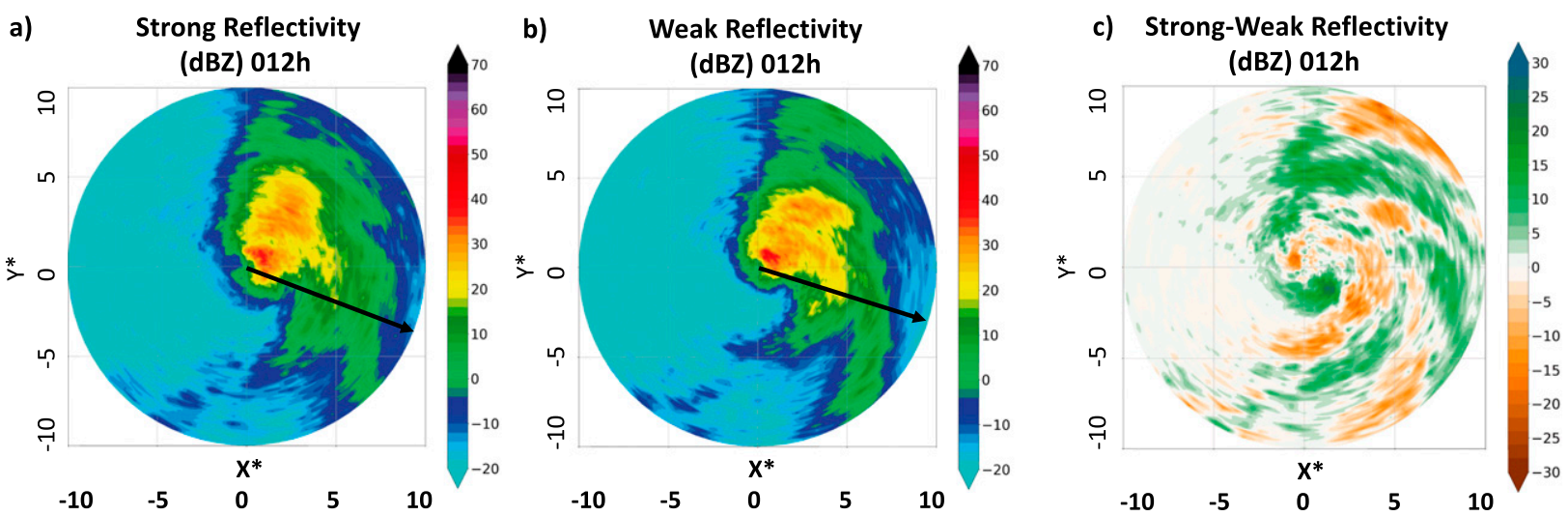

FIG. 11. (a) Composite of 4-km reflectivity ( $\mathrm{dBZ})$ at $12 \mathrm{~h}$ for the 20 "strong" members based on intensity at hour 60 . The horizontal coordinate system is normalized by the $850-\mathrm{hPa}$ radius of maximum wind (RMW). The mean shear vector from the strong members is shown in the black arrow. (b) As in (a), but for the "weak" members. (c) The difference in reflectivity between the strong and weak members.

Consistent with the composite figures, there is virtually no difference in the downshear moisture. However, in the west/upshear region, starting at around $12 \mathrm{~h}$, there is an appreciable difference between the strong and weak members, with the strong members having more moisture. However, based on one-tailed $t$ tests, the differences did not become statistically significant until around $30 \mathrm{~h}$. The fact that the difference is not significant initially implies that the change in moisture is potentially related to other structural evolution of the TC, which will be quantified next. The overall trend is for the western and northeast humidity to approach each other as the TC symmetrizes throughout the forecast period. This process happens in both strong and weak members, but is more rapid in the strong members.

\section{2) STRUCTURE METRICS}

To further quantify the structural differences seen in the strong/weak composites, comparisons of the structure metrics listed above (vortex tilt, symmetry, and closure) were made between the strong and weak members. The comparisons for the strong and weak members are shown in Table 2 based on the structure metrics at hours 12 and 36 (compared with the full time evolution shown in Fig. 8). Several basic metrics (Pmin, RMW, and shear) are also listed. The differences between the strong and weak groups are evaluated by one-tailed $t$ tests.

At hour 12 , there are surprisingly very small differences between the sets. The shear is nearly identical, over $22 \mathrm{kt}\left(11 \mathrm{~m} \mathrm{~s}^{-1}\right)$ for both groups. The initial RMW is slightly smaller for the strong group, indicating development of a more compact core. This earlier contraction of the RMW could be part of the reason for the earlier/stronger intensification (e.g., Chen et al. 2018). However, this difference is not statistically significant. In addition, none of the structure metrics show statistically significant differences. With the composites showing more moisture and enhanced precipitation for a)

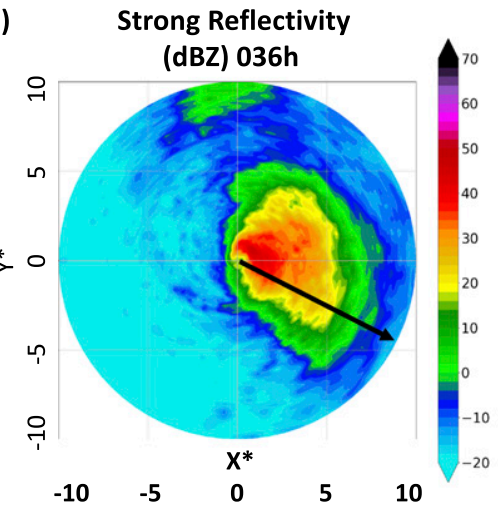

b)

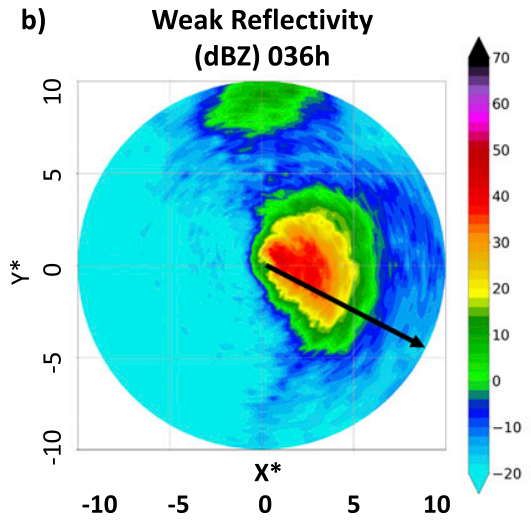

c) Strong-Weak Reflectivity

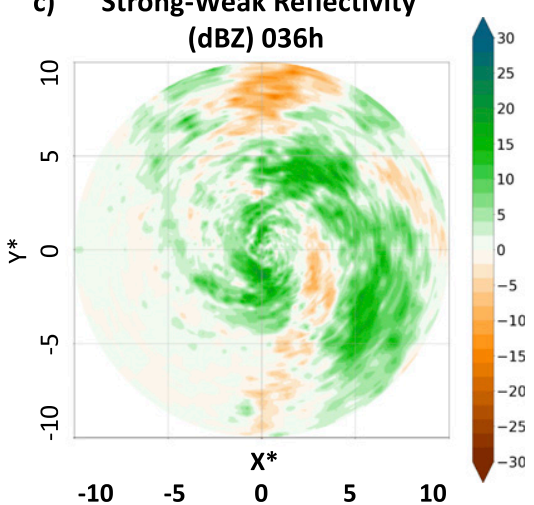

FIG. 12. As in Fig. 11, but valid at $36 \mathrm{~h}$. 
a)

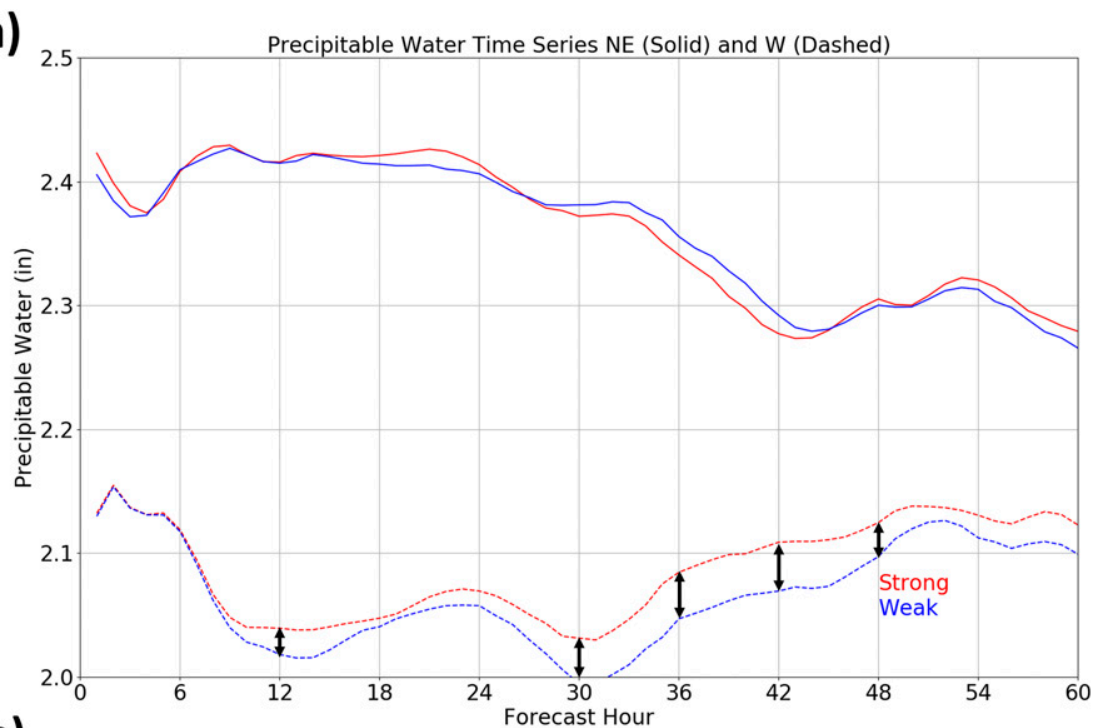

b)

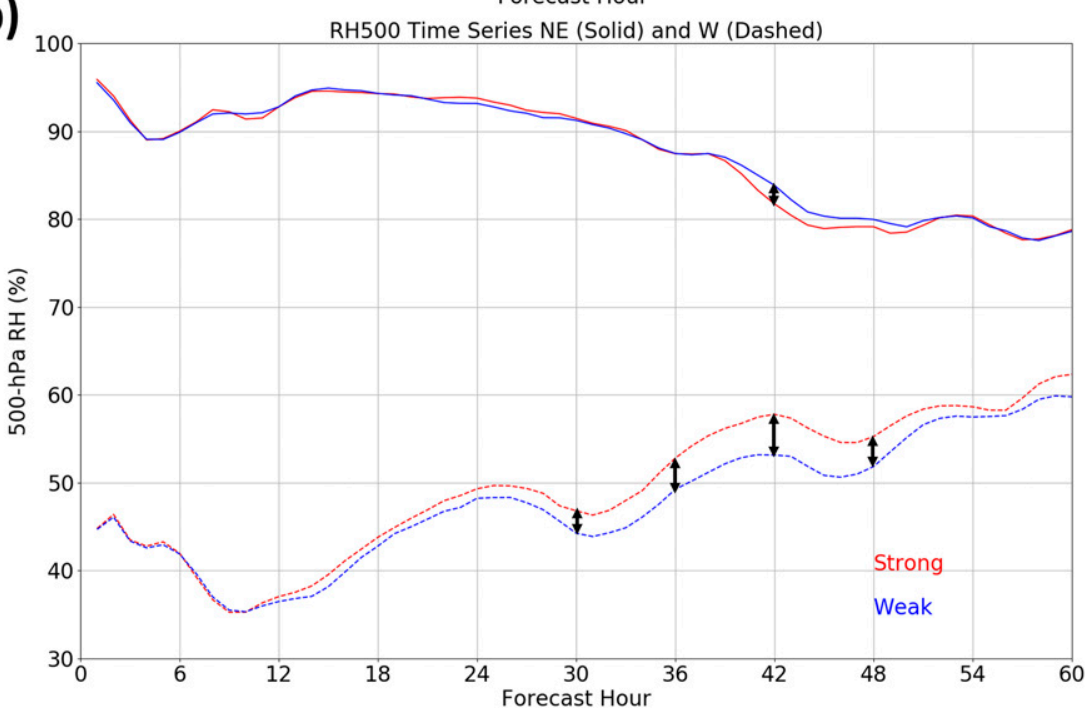

FIG. 13. (a) Time series of precipitable water in the northeast (solid) and west (dashed) quadrants for the strong and weak member means. The precipitable water is averaged over an annulus from 200 to $600 \mathrm{~km}$ from the TC center. Black brackets denote forecast hours (in 6-h increments) where the differences are statistically significant $(p<0.05)$. (b) As in (a), but for 500-hPa relative humidity.

the strong members, it appears that this was not yet reflected in the structure of the inner core, at least not in all cases.

At hour 36, the picture is very different. As shown in the composites, the shear was slightly lower for the strong members, but still over $22 \mathrm{kt}\left(11 \mathrm{~m} \mathrm{~s}^{-1}\right)$; which was stronger than at the beginning of the RI period at hour 12. The RMW was smaller and Pmin lower for the strong members, indicating that these members already had a more developed TC with a more robust core that was able to strengthen further despite marginal conditions in the large-scale environment. The strong members, unsurprisingly, had a significantly smaller vortex tilt. This is generally consistent with the idealized ensemble shown in Miyamoto and Nolan (2018), in which ensemble members with a more upright vortex and smaller RMW were more likely to experience rapid intensification. The structure metrics show several other key differences as well. The precipitation symmetry was significantly greater for both metrics for the strong cases, as well, indicating more wrapping of precipitation, consistent with the reflectivity composites shown above. The closure metric was also slightly higher for the strong case average, although the differences were only 
marginally significant for this metric. Based on the lack of significant differences in the strong and weak groups at hour 12 , but much stronger relationships at hour 36 , it appears that the period between hours 12 and 36 was key for evolution of the vortex.

\section{3) LAG RELATIONSHIP BETWEEN VORTEX TILT AND UPSHEAR HUMIDITY}

The analysis above highlights the importance of both vortex dynamical structure (i.e., tilt) and thermodynamic parameters (moisture). However, this leads to the question of how these two aspects are related, and what the relative lag is between the two. To help answer that question, Fig. 14 shows lag correlations between the $500-\mathrm{hPa}$ humidity in the western/upshear quadrant and the vortex tilt metric. The correlations are presented as box plots illustrating the relationship for each member between $-6 \mathrm{~h}$ lag (humidity leading) and $+6 \mathrm{~h}$ lag (tilt leading). The plots are also separated into the strong and weak members. The correlations are relatively strong at all leads, due to the overall trend for a decrease in tilt and increase in upshear moisture (Fig. 13) seen in most or all members. For the strong group, the highest correlation and lowest spread is at $+2 \mathrm{~h}$, and the correlations with positive lag are generally slightly larger than those with negative lag. For the weak group, the overall correlations are slightly lower and the spread is slightly higher, indicating a more diverse structure response. The strongest relationship is still at $+2 \mathrm{~h}$, which indicates that for this particular case the tilt seemed to be the leading indicator, with the changes in moisture following. However, given that large changes in vortex structure, humidity, and intensity were ongoing during this period for Michael, a feedback between these processes was certainly occurring. It is also worth noting that this analysis only considers tilt magnitude. Further analysis that also examines whether tilt orientation has any relationship with humidification is beyond the scope of this study but would be worthy of exploration.

\section{4) IMPACT OF INITIAL CONDITIONS AND EARLY EVOLUTION}

The lag correlations and other analyses lead to the question of how much of the differences between ensemble members was due to differences in the initial vortex structure versus how the vortex evolved after initialization. To help address this question, several structure and environmental variables are correlated with the intensity at $60 \mathrm{~h}$. Specifically, the $850-\mathrm{hPa}$ RMW, 850-hPa vorticity within a radius of $50 \mathrm{~km}$ from the center, and precipitable water in the western quadrant in a region $50-100 \mathrm{~km}$ form the center are evaluated. The correlations are calculated at the first output time $(1 \mathrm{~h})$ and then every $6 \mathrm{~h}$ from 6 to $60 \mathrm{~h}$. Results are shown in Table 3. For all variables, the correlations are strongest closer to $60 \mathrm{~h}$ and weaker closer to initialization, indicating that vortex evolution despite the shear was a key aspect of member differences. However, there are some indications that early vortex structure was important as well. Specifically, $850-\mathrm{hPa}$ vorticity at the initial time $(1 \mathrm{~h})$ was significantly correlated with the $60 \mathrm{~h}$ intensity. This indicates that a stronger early vortex was more likely to resist the shear and intensify later. However, the correlation for RMW is not significant at $1 \mathrm{~h}$ but becomes significant around $18 \mathrm{~h}$, indicating that the early evolution after initialization was also important. Finally, although upshear moisture in the nearstorm environment was a factor, as evidenced by the correlations at hours 30-48, there was little relationship between the peak intensity and the early moisture. This seems to indicate, as the lag correlations also showed, that moisture was responding to the initial strength and subsequent evolution of the vortex as it resisted the shear and attempted to align and intensify.

\section{5) CASE STUdy OF A STRONG AND WEAK MEMBER}

To further explore the structural differences illustrated in the strong/weak composites and metric comparisons, two individual members are selected, one from each of the strong/weak groups. The first member (Strong01) deepened by $23 \mathrm{hPa}$ between hours 12 and 36 and then $43 \mathrm{hPa}$ between hours 36 and 60 (Fig. 15a). It reached a peak intensity of $922 \mathrm{hPa}$ at hour 62 , close to the observed minimum pressure of $919 \mathrm{hPa}$. The other member (Weak01) only deepened by $7 \mathrm{hPa}$ from hours 12-36 and only deepened by $10 \mathrm{hPa}$ from hours 36-60. The minimum pressure of $977 \mathrm{hPa}$ at hour 63 was $58 \mathrm{hPa}$ weaker than the observed minimum of $919 \mathrm{hPa}$. The synoptic and structural evolution of the two members are compared and also compared with observations from NOAA reconnaissance flights when available.

Figure 15 shows time series of minimum pressure, shear, mid- and low-level vortex strength as measured by the mean tangential wind at the RMW, vortex tilt, symmetry, and closure for the strong and weak members from hours 1-72, past the landfall for both cases. The shear evolution was very similar between the two members, with shear starting off high [ $\left.>20 \mathrm{kt}\left(10 \mathrm{~m} \mathrm{~s}^{-1}\right)\right]$ and then decreasing later in the forecast period. In fact, the shear was slightly greater for Strong01 during the period from hours $24-48$ when the two members diverged in intensity. Despite the similar large-scale shear, the mid- and low-level vortices strengthened much more in Strong01. In this "moderate shear regime," slight differences in shear and the TC response may manifest in large structural differences. For example, the tilt 
a) Tilt vs. Upshear Moisture Correlations (Strong Members)

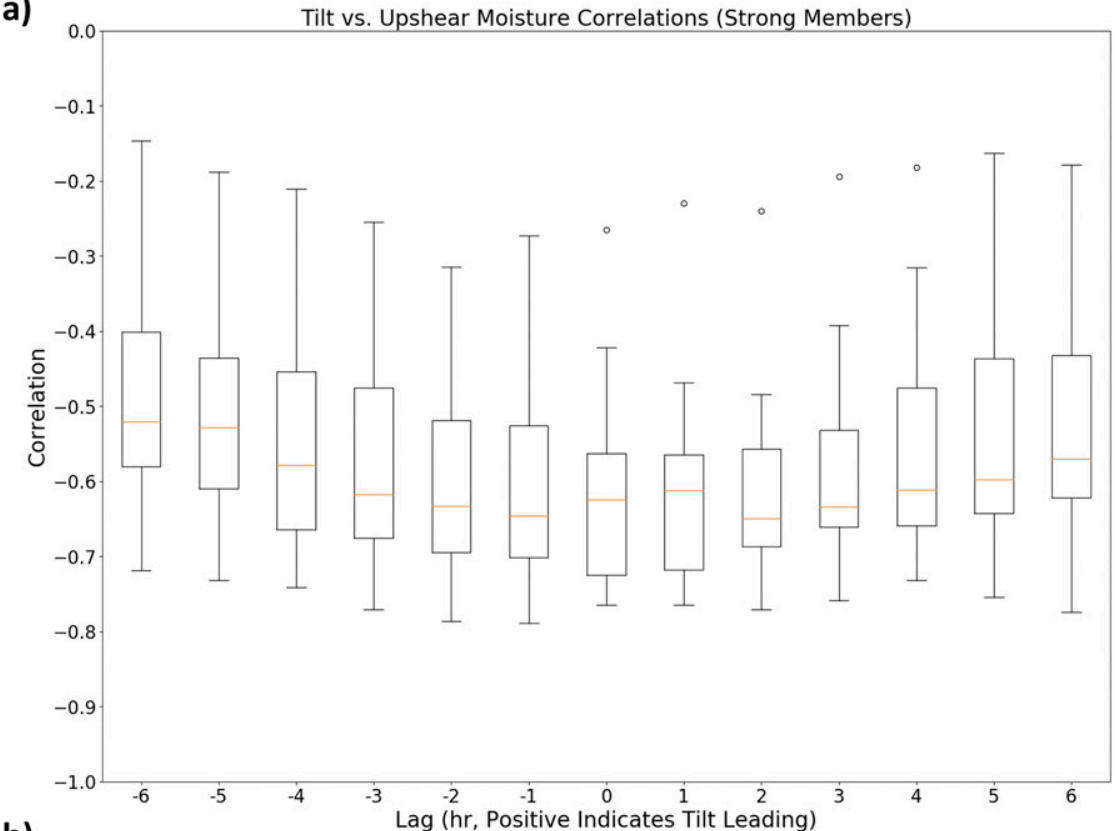

b)

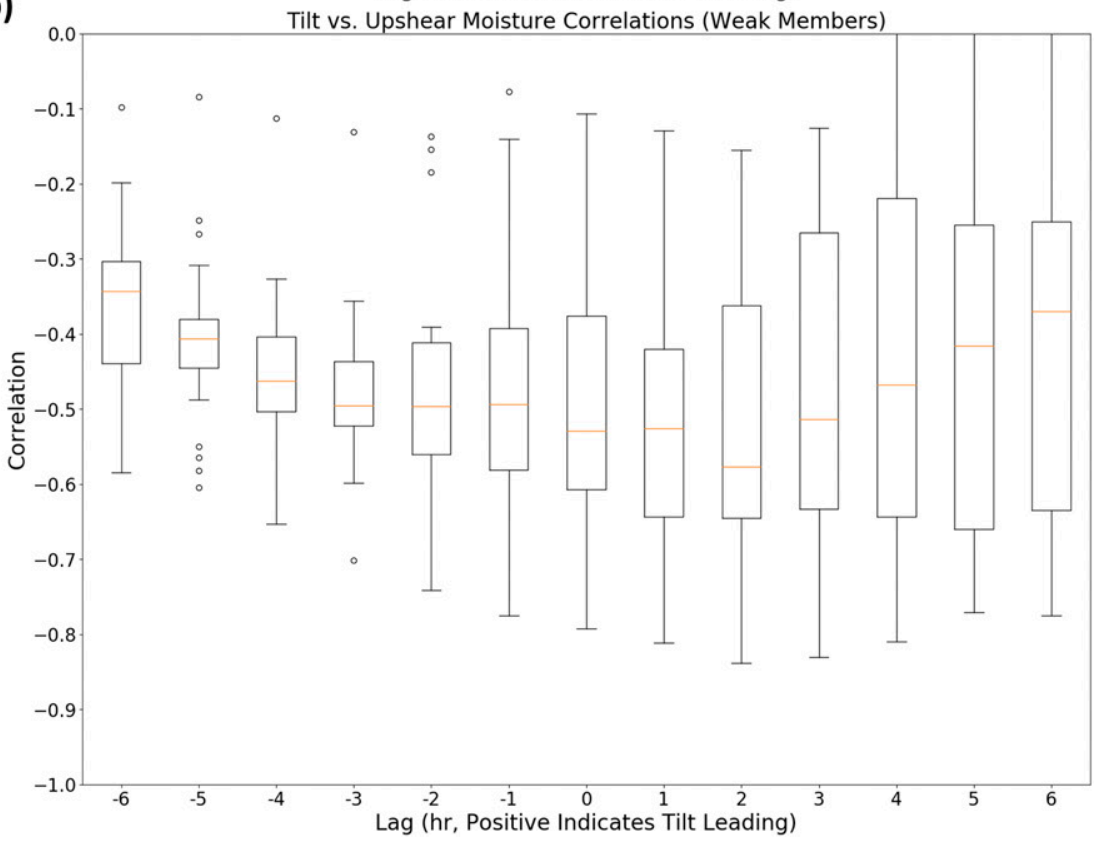

FIG. 14. (a) Boxplots of the correlation between vortex tilt and western quadrant 500-hPa humidity for the strong members. Positive lag indicates tilt leading, negative lag indicates humidity leading. The orange line shows the median. (b) As in (a), but for the weak members.

decreased in both members from hours 12-24, but spiked back up in the weak member around the same time intensification leveled off. The storm also took much longer to symmetrize in the weak member, with an initial symmetrization attempt around hours 18-24 that was not sustained. In Strong01, the symmetry reached $\sim 0.5$ several times from hours $12-36$ during a period of significant intensification, but it did not reach 0.5 in the weak member until hour 60 as the storm approached landfall. A similar divergence in closure was noted after hour 24, where the eyewall in Strong01 was 50\%-100\% closed for the rest of the period before landfall, but closure did not reach $50 \%$ until just prior to landfall in Weak01. Table 4 lists the structure metrics for each member at hour 12 and 36. At hour 12, in strong members, the tilt was about half as small, and the eyewall was 
TABLE 3. Correlations between several variables at different forecast hours of the ensemble set and the peak intensity at $60 \mathrm{~h}$. The variables correlated with peak wind are the $850-\mathrm{hPa}$ RMW, $850-\mathrm{hPa}$ vorticity in the region from the center to $r=50 \mathrm{~km}$, and precipitable water in the western quadrant from $r=50-100 \mathrm{~km}$. Relationships that are significant at the $95 \%$ level are italicized, and relationships that are significant at the $99 \%$ level are bold and italicized.

\begin{tabular}{cccc}
\hline $\begin{array}{c}\text { Forecast } \\
\text { hour }\end{array}$ & $\begin{array}{c}\text { Correlation } \\
\text { with } 850-\mathrm{hPa} \\
\text { RMW }\end{array}$ & $\begin{array}{c}\text { Correlation } \\
\text { with } 850-\mathrm{hPa} \\
\text { vorticity }\end{array}$ & $\begin{array}{c}\text { Correlation with } \\
\text { west quadrant } \\
\text { precipitable water }\end{array}$ \\
\hline 1 & -0.27 & $\mathbf{0 . 4 2}$ & 0.18 \\
6 & -0.35 & $\mathbf{0 . 5 9}$ & 0.08 \\
12 & -0.24 & $\mathbf{0 . 4 7}$ & 0.34 \\
18 & $-\mathbf{0 . 5 2}$ & $\mathbf{0 . 5 8}$ & 0.29 \\
24 & $-\mathbf{0 . 4 1}$ & $\mathbf{0 . 5 8}$ & 0.09 \\
30 & $-\mathbf{0 . 4 5}$ & $\mathbf{0 . 7 0}$ & $\mathbf{0 . 4 9}$ \\
36 & $-\mathbf{0 . 5 3}$ & $\mathbf{0 . 7 0}$ & $\mathbf{0 . 5 8}$ \\
42 & $-\mathbf{0 . 7 6}$ & $\mathbf{0 . 7 8}$ & $\mathbf{0 . 4 1}$ \\
48 & $-\mathbf{0 . 7 3}$ & $\mathbf{0 . 8 3}$ & $\mathbf{0 . 6 1}$ \\
54 & $-\mathbf{0 . 7 8}$ & $\mathbf{0 . 8 8}$ & 0.123 \\
60 & $-\mathbf{0 . 7 2}$ & $\mathbf{0 . 8 7}$ & 0.27 \\
\hline
\end{tabular}

about 4 times as symmetric as the weak ones. In addition, the eyewall was almost half closed (0.49) in the strong member but just over a third closed (0.38) in the weak member. At hour 36, the vortex had almost no tilt $(6.7 \mathrm{~km})$ in the strong member, but was still tilted $(26.9 \mathrm{~km})$ in the weak member. The eyewall reflectivity was much more symmetric in the strong member, and the eyewall was almost $3 / 4$ closed, while in the weak member the eyewall was extremely asymmetric and still only about $1 / 3$ closed. These structural differences did not appear to be due to any differences in large-scale shear, as the shear at hour 12 was only $0.7 \mathrm{kt}\left(0.4 \mathrm{~m} \mathrm{~s}^{-1}\right)$ higher for Weak01, and was actually $2.7 \mathrm{kt}\left(1.4 \mathrm{~m} \mathrm{~s}^{-1}\right)$ higher for Strong01 at hour 36. The ability of the TC to vertically align and symmetrize despite the strong largescale shear played a key role in the speed of deepening.

To assess whether the forecast structural changes were consistent with what occurred in the real TC, the model forecasts were compared directly with radar observations from the NOAA P-3 flights into Michael. Figures $16 \mathrm{a}-\mathrm{c}$ show the $4-\mathrm{km}$ radar reflectivity from the strong and weak members, and also from a pass across the eye from one of the flights around 0100 UTC 9 October This is $31 \mathrm{~h}$ of the forecasts, as there was no flight at $36 \mathrm{~h}$. The radar coverage does not fully capture the entire storm, but is enough to capture the eyewall region used to evaluate the structure metrics (black circles). The strong member is more in line with observations, with asymmetric stronger precipitation in the northeast quadrant and a core of strong precipitation wrapping around most of the eyewall on the west side (upshear). In the weak member, both the inner core and outer core differ from observations, with no precipitation wrapping around the west side of the eyewall, and most of the outer-core precipitation confined to the southeast quadrant. This difference is consistent with the findings of Rogers et al. (2016) and Leighton et al. (2018) in Hurricane Edouard, where intensification was associated with convection wrapping into the upshear quadrant. Figures $16 \mathrm{~d}-\mathrm{f}$ illustrate the vortex tilt from the model and radar at the same time period, showing the $850-$ and $500-\mathrm{hPa}$ winds from the model $(1.5$ and $5.5 \mathrm{~km}$ from the radar). Although the coverage is not perfect, the radar shows that Michael's low-level and midlevel centers were close to vertically aligned at this time, as in the strong member. In the weak member, the misalignment is apparent, with the 500 -hPa center noticeably displaced to the southeast (generally downshear). This consistency in structure between the strong member and the observed TC provides confidence that the structural changes leading to RI in the strong members were similar to those in the real TC.

To further investigate the structural differences between Strong01 and Weak01, and connect the differences to the composites, the moisture differences between the two members are analyzed next. Figure 17 shows radius-height cross sections of relative humidity in the along-shear and across-shear directions for Strong01 and Weak01 at hour 36. Interestingly, the overall pattern is very similar between the two members, with a generally moist deep-layer column left of shear and downshear, with an area of dry air protruding toward the core between about 500 and $300 \mathrm{hPa}$. Past studies have suggested that such dry air can inhibit TC intensification or cause weakening as it approaches the inner-core region (e.g., Shu and Wu 2009; Ge et al. 2013), especially if the boundary layer fluxes are not sufficient for recovery of $\theta_{e}$ (e.g., Zhang and Rogers 2019). Midlevel dry air like this can also cause ventilation and associated downdrafts that (e.g., Tang and Emanuel 2012) that hinder development of TCs in shear. Based in on the data, one key difference between the members is that the dry-air intrusion penetrates all the way to the center $(r=0)$ in Weak01, with dry air puncturing the eyewall on the upshear/left-of-shear side. This could be due to a combination of stronger radial inflow and/or the vertical tilt of the vortex. However, in Strong01, the dry air and inflow stops at $\sim 60 \mathrm{~km}$ from the surface center, and the eyewall is still intact. The intact core allows this member to continue to intensify at a stronger rate. This analysis does not show details of the exact timing and causality of the relationship between vortex tilt and development of upshear precipitation, but the lag correlations discussed previously indicate that the change in tilt may be the leading driver. 

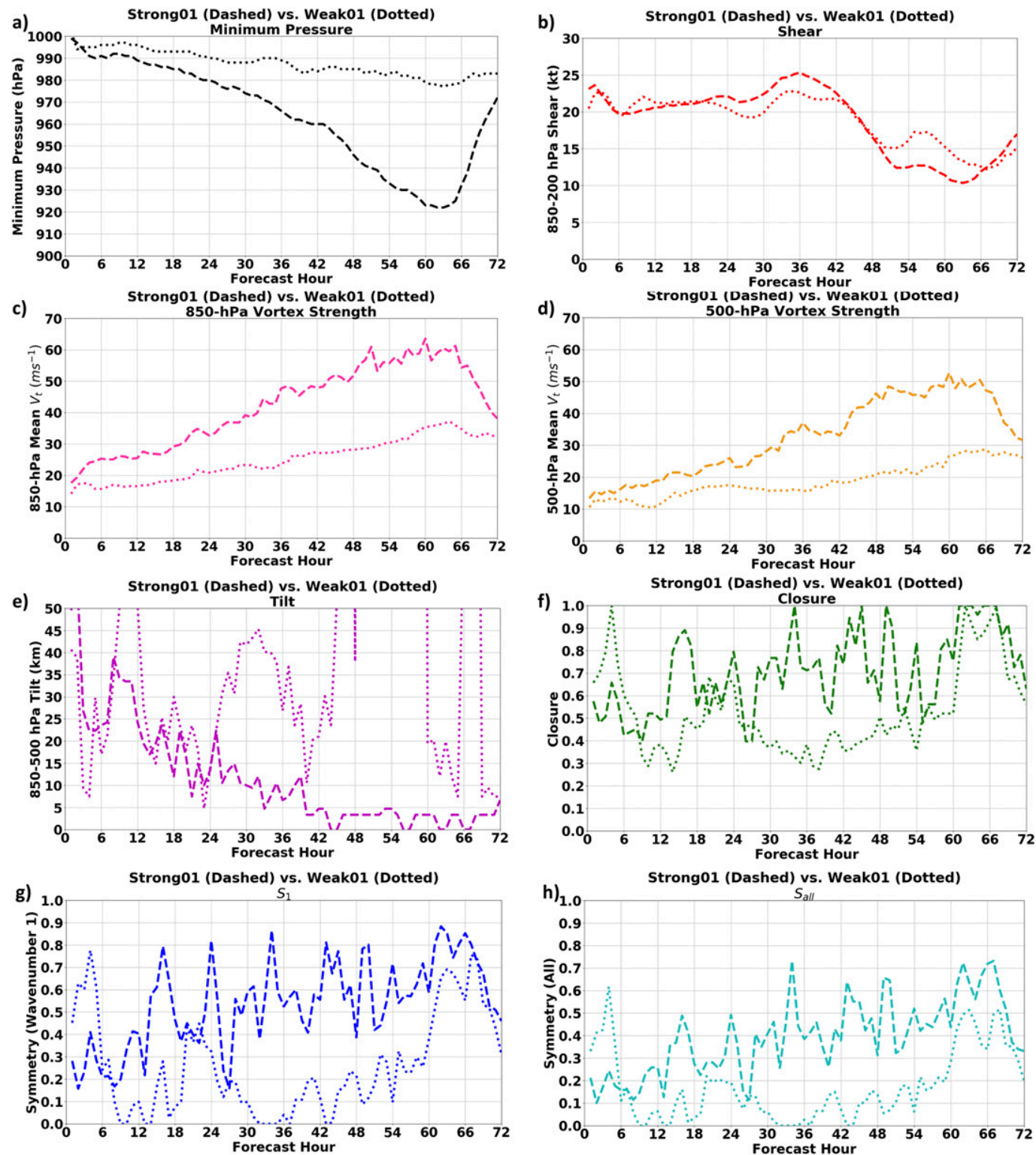

FIG. 15. (a) Minimum central pressure (hPa) from hours 1-72 for Strong01 (dashed) and Weak01 (dotted). (b) As in (a), but showing 850-200-hPa vertical wind shear. (c) As in (a), but showing 850-hPa vortex strength defined by the mean tangential wind at the 850-hPa RMW. (d) As in (a), but showing 500-hPa vortex strength defined by the mean tangential wind at the 500-hPa RMW. (e) As in (a), but showing 850-500-hPa vortex tilt. (f) As in (a), but showing closure. (g) As in (a), but showing $S_{1}$. (h) As in (a), but showing $S_{\text {all }}$.

To examine this point a bit further, area averages of relative humidity at 500 and $850 \mathrm{hPa}$ were calculated relative to the local centers, rather than the surface center as in Fig. 17, in the $r=30-70 \mathrm{~km}$ range. For Strong01 at $36 \mathrm{~h}$, the mean $850-\mathrm{hPa}$ RH was $90.2 \%$ and the mean $500-\mathrm{hPa}$ RH was $83.7 \%$ in the tilt-adjusted annuli. For Weak01, the mean $850-\mathrm{hPa}$ RH was $92.9 \%$ and the mean $500-\mathrm{hPa}$ RH was $85.1 \%$. The lack of difference when accounting for the differences in center location seems to indicate that, in this case, the vortex tilt was the main driver of the dry intrusion, consistent with the correlations discussed previously. In the future, it would be useful to examine the exact impact of dry air on the structure evolution of TCs in these and other simulations, and how vortex humidification, ventilation, and tilt coevolve.

A final comparison between the strong and weak members involved analysis of convective bursts in Strong01 and Weak01. While it was clear from the reflectivity and moisture composites that there was more 
TABLE 4. Structure metrics tilt ( $\mathrm{km})$, symmetry, and closure, as well as basic metrics minimum central pressure (hPa), RMW (km), and shear (kt) at hours 12 and 36 for the individual strong and weak members.

\begin{tabular}{lccccccc}
\hline \hline & Pmin $(\mathrm{hPa})$ & RMW $(\mathrm{km})$ & Shear $(\mathrm{kt})$ & Tilt $(\mathrm{km})$ & $S_{\text {all }}$ & $S_{1}$ & Closure \\
\hline & & & Hour 12 & & & & \\
Strong & 989 & 57 & 20.6 & 24.3 & 0.26 & 0.40 & 0.49 \\
Weak & 996 & 66 & 21.3 & 51.0 & 0.06 & 0.10 & 0.38 \\
& & & & & & \\
Strong & 966 & 33 & 25.3 & 6.7 & 0.38 & 0.53 & 0.71 \\
Weak & 989 & 51 & 22.6 & 26.9 & 0.03 & 0.04 & 0.38 \\
\hline
\end{tabular}

precipitation upshear for the intensifying members (and this was highlighted by the comparison between Strong01 and Weak01), it is worthwhile to examine whether this is due to active convection upshear in Strong01 or simply precipitation wrapping around after being generated by updrafts downshear. Convective bursts (CBs) were defined based on a layer-mean vertical velocity (as in Hazelton et al. 2018a,b). The layer used here was $500-200 \mathrm{hPa}$. Two separate thresholds of vertical velocity were examined, 3 and $5 \mathrm{~ms}^{-1}$. Since multiple previous studies have demonstrated that innercore CBs are the most favorable for intensification (e.g., Rogers et al. 2013), only CBs in the inner $50 \mathrm{~km}$ were included in the analysis.

Figure 18 shows the CB counts in each of four shearrelative quadrants: downshear-left (DSL), upshear-left (USL), upshear-right (USR), and downshear-right (DSR). Counts for both thresholds are shown for Strong01 and a)

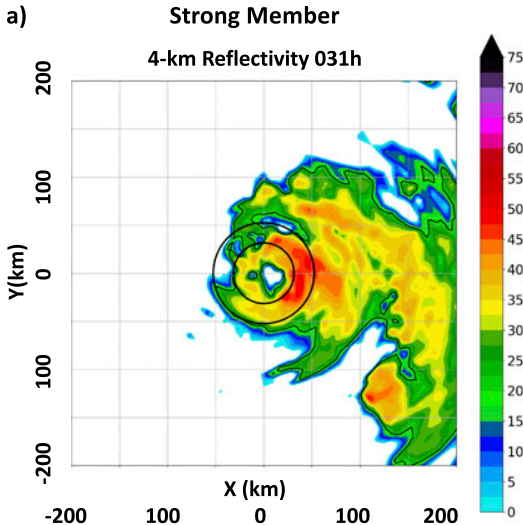

d) Strong Member 850-hPa Streamlines (Red),

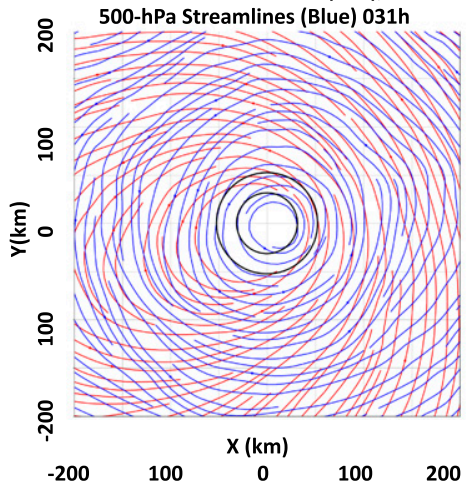

b)

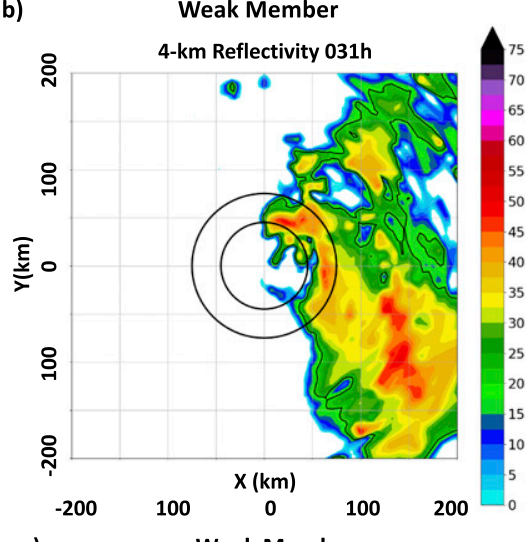

e)

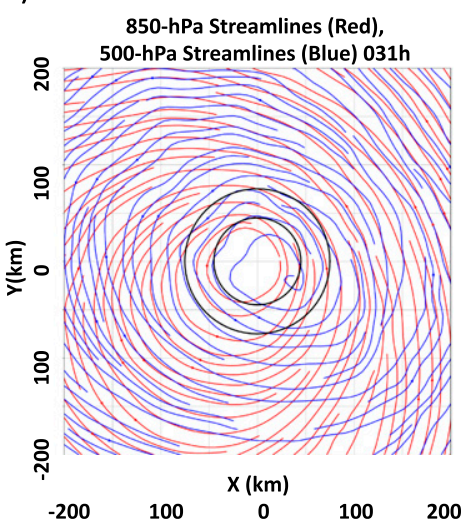

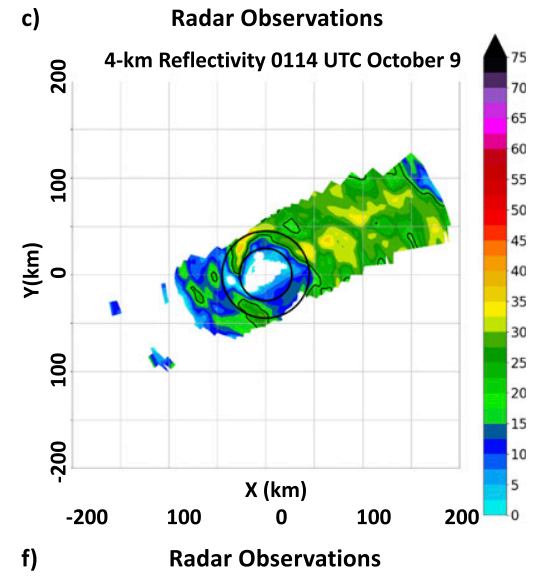

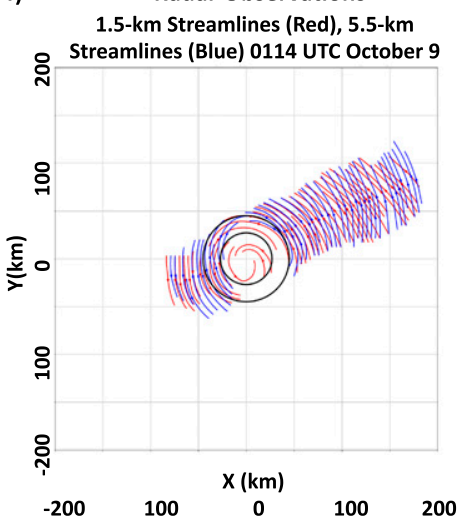

FIG. 16. (a) 4-km reflectivity for the strong individual member at hour 31 . The black rings show the $R^{*}=0.75-1.25$ annulus used to calculate symmetry and closure. (b) As in (a), but for the weak individual member. (c) 4-km reflectivity from the NOAA P-3 flight for a pass across Michael centered at 0114 UTC 10 Oct 2018. (d) 850-hPa streamlines (red) and 500-hPa streamlines (blue) for the strong individual member at hour 31. The black rings show the $R^{*}=0.75-1.25$ annulus. (e) As in (d), but for the weak individual member. (f) $1.5-\mathrm{km}$ streamlines (red) and 5.5-km streamlines (blue) from the NOAA P-3 flight for a pass across Michael centered at 0114 UTC 10 Oct 2018. The black rings show the $R^{*}=0.75-1.25$ annulus. 

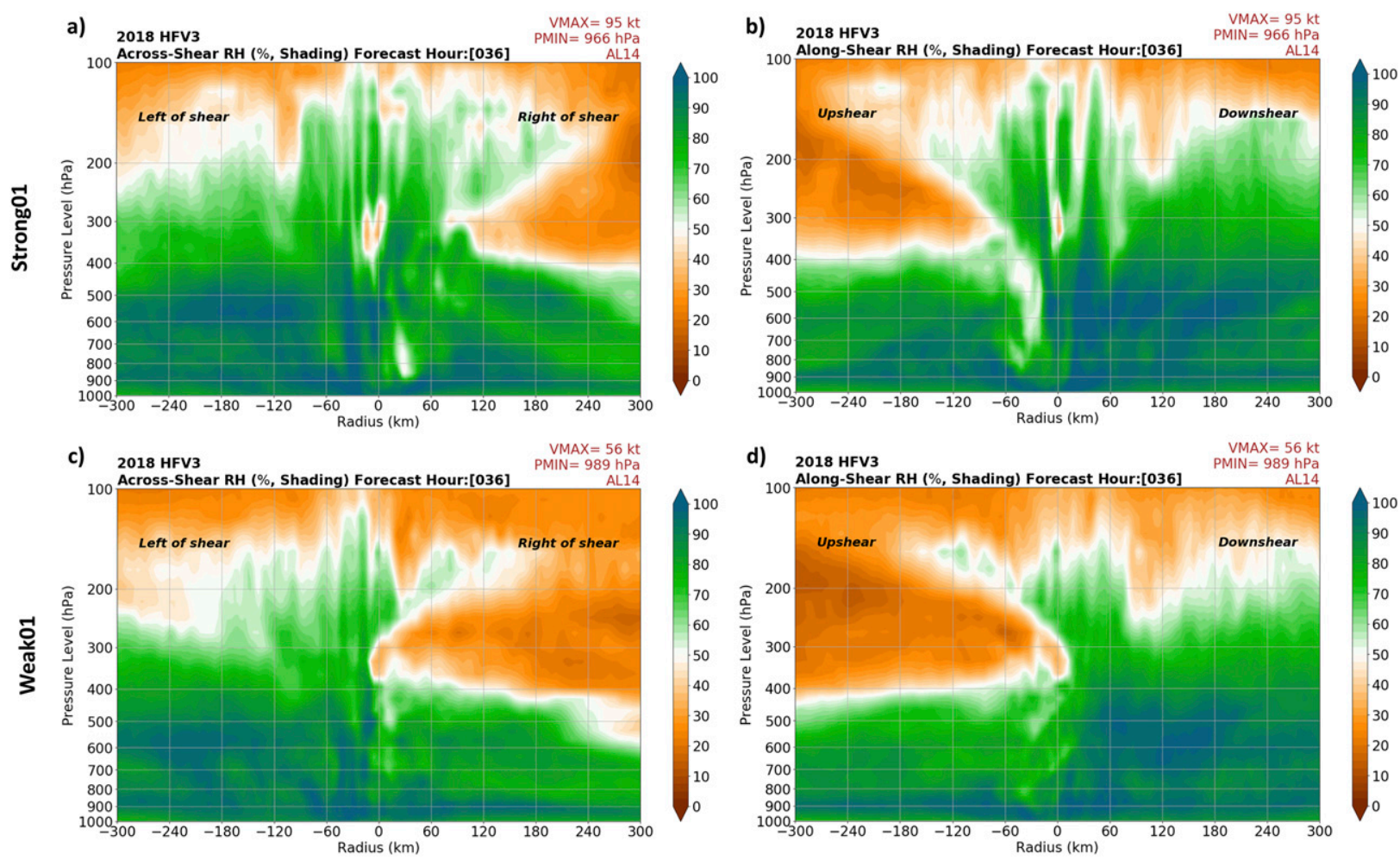

FIG. 17. (a) Cross-shear cross section of relative humidity (\%, shading) for the strong individual member at hour 36. (b) Along-shear cross section of relative humidity for the strong individual member at hour 36. (c) As in (a), but for the weak individual member. (d) As in (b), but for the weak individual member.

Weak01. For both members, the biggest initial peak is around $36 \mathrm{~h}$, the period examined in detail above. However, the spatial distribution of CBs is very different between the two members. For Weak01, almost all of the $5 \mathrm{~m} \mathrm{~s}^{-1}$ CBs were in the DSL quadrant, typically the shear-relative quadrant where convection is strongest (e.g., Rogers et al. 2013; Reasor et al. 2013). Even for the $3 \mathrm{~m} \mathrm{~s}^{-1}$ threshold, most CBs were located DSL, and there were very few USL, and none USR or DSR. Clearly, there was a strong shear-relative gradient in convective activity for this member. For Strong01, the $\mathrm{CB}$ pattern is much different. The peak in $\mathrm{CBs}$ at the $5 \mathrm{~m} \mathrm{~s}^{-1}$ threshold is actually in the USL quadrant, and there are even a few in the USR quadrant, which typically is the least convectively active due to shear-relative asymmetry. Using the $3 \mathrm{~m} \mathrm{~s}^{-1}$ threshold, there are CBs in all 4 shear-relative quadrants for Strong 01 at $36 \mathrm{~h}$, and the total number are also greater than in Weak01. The pattern is similar at other forecast hours. This indicates that Strong01 had more inner-core convective activity than Weak01, and the convective activity was also distributed more symmetrically around the eyewall, despite the shear being very similar between the two members. The precipitation symmetry differences were therefore likely not just due to differences in how precipitation wrapped upshear, but also local generation of precipitation by strong updrafts. The greater number of total CBs, which is likely both a cause and result of the greater upshear humidity, also provides more heating in Strong01, allowing it to intensify despite the shear.

\section{Discussion and conclusions}

The results of this study demonstrate the capability of an FV3GFS ensemble system to simulate the structure and intensity change of Hurricane Michael in moderate to high vertical shear. The track forecasts of Michael were slightly under dispersive, but the wide range of intensity forecasts from the ensemble members allowed for detailed analysis of the differences between strong and weak members. To quantify the structural evolution, structure metrics were derived, including vortex tilt as well as symmetry and closure metrics to examine the evolution of inner-core precipitation. We found that TC intensified as the symmetry increased and tilt decreased and then continues to strengthen and become more symmetric as shear decreases prior to landfall. Tilt is the leading factor with the changes in moisture following. As Rappaport et al. (2010) showed, most major hurricanes approaching landfall in the Gulf of Mexico tend to 
a) $5 \mathrm{~ms}^{-1}$ Threshold

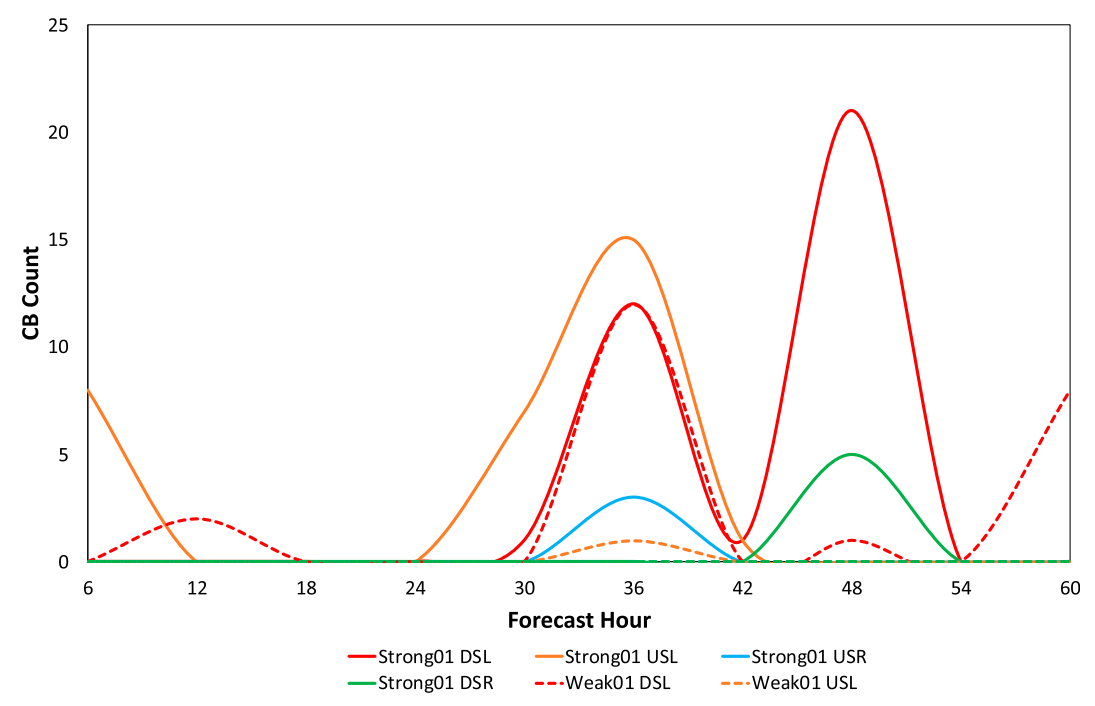

b)

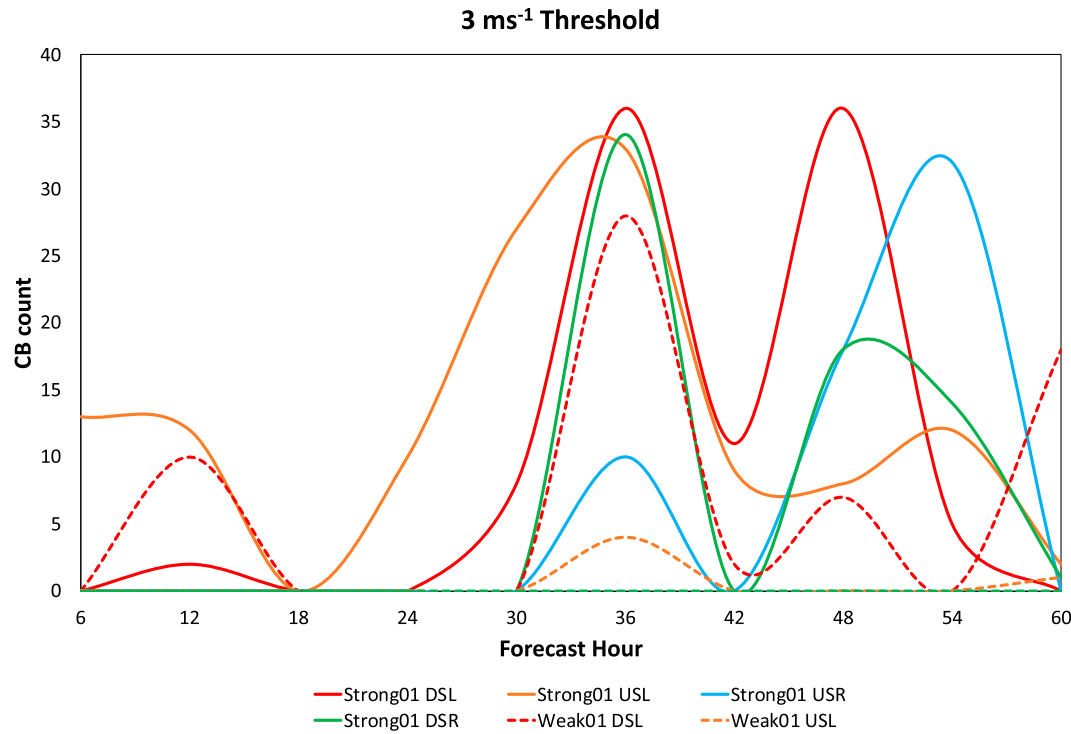

FIG. 18. (a) Convective burst counts in each of 4 shear-relative quadrants (downshear-left, red, upshear-left, orange, upshear-right, blue, and downshear-right, green) for Strong01 (solid) and Weak01 (dashed). The CB counts are based on a threshold of $5 \mathrm{~m} \mathrm{~s}^{-1}$ averaged in the 500-200-hPa layer. (b) As in (a), but using a threshold of $3 \mathrm{~m} \mathrm{~s}^{-1}$.

weaken prior to reaching land, due to a combination of upwelling and increased vertical shear. In contrast, our current study showed Michael was able to strengthen despite moderate vertical shear through the alignment and humidification of the vortex. In addition, the large-scale reduction in shear and favorable jet interaction as Michael approached the coast further aided the final period of intensification. Future work will focus more on this last stage of intensification associated with the trough interaction and the oceanic effects.
By grouping strong and weak members, some of the key factors that allowed Michael to intensify despite the potentially adverse shear were revealed. For the members that intensified the most from hours 12-36, differences in environmental moisture were key, with shear and structural differences relatively small between weak and strong members; however, by hour 36 , the structural evolution of the storm became more important. The members that intensified the most from hours 36-60 had a more symmetric and closed eyewall and, also, a more upright vortex. This development of an aligned 
and symmetric core appears to be a key for RI of moderately sheared TCs, as suggested by other studies using both real and idealized numerical simulations (e.g., Miyamoto and Nolan 2018). The low- to midlevel moisture continued to be a significant difference, with stronger members having more moisture upshear. Similar differences in upshear moisture, convection, and precipitation have been noted in observational studies, both case studies (e.g., Rogers et al. 2016; Nguyen et al. 2017) and studies based on multiple TCs (e.g., Zagrodnik and Jiang 2014; Alvey et al. 2015). In this study, we further examined this relationship by exploring the lag correlation between vortex tilt and upshear humidification. While the relationship was strong for various lags and leads, the strongest relationship was found with tilt leading. Interestingly, the relationship was stronger for the strong ensemble members, indicating a more robust response of the TC precipitation to the vortex structure. The details of this complex interaction are worthy of further investigation but beyond the scope of this study.

The further detailed examination of a typical strong member (Strong01) and a weak member (Weak01) of 41 ensemble members highlighted such a structural evolution that enabled the storm to intensify. Strong01 became aligned much more quickly than Weak01, and its precipitation also symmetrized much faster. A comparison with NOAA P-3 radar data indicated that the wrapping precipitation in the upshear region and vortex tilt in Strong01 was more consistent with the observed TC as has been observed in other TCs that intensify in shear (e.g., Chen and Gopalakrishnan 2015; Zawislak et al. 2016; Nguyen et al. 2017; Zhang and Rogers 2019). Both environmental moisture and vortex-scale processes appear to be key in these differences between the members. Mid- to upper-level dry air presented in the near-storm environment for both members, but penetrated to the core only in Weak01. In Strong01, this was likely due to the earlier vortex alignment that built the resilience of intensification to the dry-air intrusion although the two processes feedback on each other. The environment was also favorable in Strong01 for the development of convective bursts, which were both more numerous and much more symmetrically distributed around the TC than in Weak01. The convective burst provides the additional energy to maintain intensification in the sheared environment.

In addition to highlighting some of the important structural changes that can lead to rapid intensification in shear, this study shows that FV3GFS is capable of simulating fundamental processes in TC evolution, such as the complicated interplay between the synoptic environment and inner-core structure in such sheared environments. The ensemble approach employed in this study will be refined as a rudimental approach for a new sophisticated data assimilation system currently under development. Along with the rapid improvements of the dynamics, physics and other aspects of FV3GFS, the approach and analysis techniques will eventually be transitioned to the next-generation Hurricane Analysis and Forecast System (HAFS).

Acknowledgments. The authors thank the NOAA Jet staff for helping to maintain and troubleshoot the highperformance computing system used for these model simulations. We are also grateful to the crews of the NOAA P3 aircraft for collecting the radar data used in this study. The authors thank Gus Alaka, Rob Rogers, and three anonymous reviewers for their comments, which helped improve upon an earlier version of the paper. Andrew Hazelton, Sundaraman Gopalakrishnan, Xuejin Zhang, Frank Marks, and Bill Ramstrom were supported by NOAA Hurricane Research Division base funding. Jun Zhang was in part supported by NSF Grants AGS-1822128 and AGS-1654831, NOAA Grants NA14NWS4680028 and NA14NWS4680030, and NASA Grant NA14NWS4680030.

\section{REFERENCES}

Alaka, G. J., X. Zhang, S. G. Gopalakrishnan, Z. Zhang, F. D. Marks, and R. Atlas, 2019: Track uncertainty in high-resolution ensemble forecasts of Hurricane Joaquin. Wea. Forecasting, 34, 1889-1908, https://doi.org/10.1175/WAF-D-19-0028.1.

Alvey, G. R., III, J. Zawislak, and E. Zipser, 2015: Precipitation properties observed during tropical cyclone intensity change. Mon. Wea. Rev., 143, 4476-4492, https://doi.org/10.1175/ MWR-D-15-0065.1.

Beven, J. L., II, R. Berg, and A. Hagen, 2019: National Hurricane Center Tropical Cyclone Report, Hurricane Michael (7-11 October 2018). Tech. Rep. AL142018, National Hurricane Center, 86 pp., https://www.nhc.noaa.gov/data/tcr/AL142018_Michael.pdf.

Bhatia, K. T., and D. S. Nolan, 2013: Relating the skill of tropical cyclone intensity forecasts to the synoptic environment. Wea. Forecasting, 28, 961-980, https://doi.org/10.1175/WAF-D-12-00110.1.

Buizza, R., J. Barkmeijer, T. N. Palmer, and D. S. Richardson, 2000: Current status and future development of the ECMWF ensemble prediction system. Meteor. Appl., 7, 163-175, https:// doi.org/10.1017/S1350482700001456.

Cangialosi, J. P., and C. W. Landsea, 2016: An examination of model and official National Hurricane Center tropical cyclone size forecasts. Wea. Forecasting, 31, 1293-1300, https://doi.org/ 10.1175/WAF-D-15-0158.1.

Chen, H., and S. G. Gopalakrishnan, 2015: A study on the asymmetric rapid intensification of Hurricane Earl (2010) using the HWRF system. J. Atmos. Sci., 72, 531-550, https://doi.org/ 10.1175/JAS-D-14-0097.1.

Chen, J.-H., and S.-J. Lin, 2013: Seasonal predictions of tropical cyclones using a $25-\mathrm{km}$-resolution general circulation model. J. Climate, 26, 380-398, https://doi.org/10.1175/ JCLI-D-12-00061.1. 
Chen, S. S., J. A. Knaff, and F. D. Marks, 2006: Effects of vertical wind shear and storm motion on tropical cyclone rainfall asymmetries deduced from TRMM. Mon. Wea. Rev., 134, 3190-3208, https://doi.org/10.1175/MWR3245.1.

Chen, X., M. Xue, and J. Fang, 2018: Rapid intensification of Typhoon Mujigae (2015) under different sea surface temperatures: Structural changes leading to rapid intensification. J. Atmos. Sci., 75, 4313-4335, https://doi.org/10.1175/JAS-D-18-0017.1.

Corbosiero, K. L., and J. Molinari, 2002: The effects of vertical wind shear on the distribution of convection in tropical cyclones. Mon. Wea. Rev., 130, 2110-2123, https://doi.org/ 10.1175/1520-0493(2002)130<2110:TEOVWS>2.0.CO;2.

DeHart, J. C., R. A. Houze, and R. F. Rogers, 2014: Quadrant distribution of tropical cyclone inner-core kinematics in relation to environmental shear. J. Atmos. Sci., 71, 2713-2732, https://doi.org/10.1175/JAS-D-13-0298.1.

DeMaria, M., and J. Kaplan, 1994: A Statistical Hurricane Intensity Prediction Scheme (SHIPS) for the Atlantic basin. Wea. Forecasting, 9, 209-220, https://doi.org/10.1175/ 1520-0434(1994)009<0209:aships >2.0.co;2.

Ge, X., T. Li, and M. Peng, 2013: Effects of vertical shears and midlevel dry air on tropical cyclone developments. J. Atmos. Sci., 70, 3859-3875, https://doi.org/10.1175/JAS-D-13-066.1.

Gray, W. M., 1968: Global view of the origin of tropical disturbances. Mon. Wea. Rev., 96, 669-700, https://doi.org/10.1175/ 1520-0493(1968)096<0669:GVOTOO > 2.0.CO;2.

Han, J., and H.-L. Pan, 2011: Revision of convection and vertical diffusion schemes in the NCEP Global Forecast System. Wea. Forecasting, 26, 520-533, https://doi.org/ 10.1175/WAF-D-10-05038.1.

—_, W. Wang, Y. C. Kwon, S. Hong, V. Tallapragada, and F. Yang, 2017: Updates in the NCEP GFS cumulus convection schemes with scale and aerosol awareness. Wea. Forecasting, 32, 2005-2017, https://doi.org/10.1175/WAF-D-17-0046.1.

Harris, L. M., and S.-J. Lin, 2013: A two-way nested global-regional dynamical core on the cubed-sphere grid. Mon. Wea. Rev., 141, 283-306, https://doi.org/10.1175/MWR-D-11-00201.1.

Hazelton, A. T., R. E. Hart, and R. Rogers, 2017a: Analyzing simulated convective bursts in two Atlantic hurricanes. Part I: Burst formation and development. Mon. Wea. Rev., 145, 30733094, https://doi.org/10.1175/MWR-D-16-0267.1.

— — — , and — 2017b: Analyzing simulated convective bursts in two Atlantic hurricanes. Part II: Intensity change due to bursts. Mon. Wea. Rev., 145, 3095-3117, https:// doi.org/10.1175/MWR-D-16-0268.1.

_ , M. Bender, M. Morin, L. Harris, and S.-J. Lin, 2018a: 2017 Atlantic hurricane forecasts from a high-resolution version of the GFDL fvGFS model: Evaluation of track, intensity, and structure. Wea. Forecasting, 33, 1317-1337, https://doi.org/ 10.1175/WAF-D-18-0056.1.

_, L. Harris, and S.-J. Lin, 2018b: Evaluation of tropical cyclone forecasts in a high-resolution version of the multiscale GFDL fvGFS model. Wea. Forecasting, 33, 419-442, https://doi.org/ 10.1175/WAF-D-17-0140.1.

Iacono, M. J., J. S. Delamere, E. J. Mlawer, M. W. Shephard, S. A. Clough, and W. D. Collins, 2008: Radiative forcing by longlived greenhouse gases: Calculations with the AER radiative transfer models. J. Geophys. Res., 113, D13103, https://doi.org/ 10.1029/2008JD009944.

Kaplan, J., M. DeMaria, and J. A. Knaff, 2010: A revised tropical cyclone rapid intensification index for the Atlantic and eastern North Pacific basins. Wea. Forecasting, 25, 220-241, https:// doi.org/10.1175/2009WAF2222280.1.
Leighton, H., S. Gopalakrishnan, J. A. Zhang, R. F. Rogers, Z. Zhang, and V. Tallapragada, 2018: Azimuthal distribution of deep convection, environmental factors, and tropical cyclone rapid intensification: A perspective from HWRF ensemble forecasts of Hurricane Edouard (2014). J. Atmos. Sci., 75, 275-295, https://doi.org/10.1175/JAS-D-17-0171.1.

Lin, S.-J., 1997: A finite-volume integration method for computing pressure gradient force in general vertical coordinates. Quart. J. Roy. Meteor. Soc., 123, 1749-1762, https://doi.org/10.1002/ QJ.49712354214.

, 2004: A "vertically Lagrangian" finite-volume dynamical core for global models. Mon. Wea. Rev., 132, 2293-2307, https:// doi.org/10.1175/1520-0493(2004)132<2293:AVLFDC>2.0.CO;2. , and R. B. Rood, 1997: An explicit flux-form semi-Lagrangian shallow-water model on the sphere. Quart. J. Roy. Meteor. Soc., 123, 2477-2498, https://doi.org/10.1002/qj.49712354416.

Lin, Y.-L., R. D. Farley, and H. D. Orville, 1983: Bulk parameterization of the snow field in a cloud model. J. Climate Appl. Meteor., 22, 1065-1092, https://doi.org/10.1175/15200450(1983)022<1065:BPOTSF $>2.0$. CO; 2 .

Matyas, C. J., S. E. Zick, and J. Tang, 2018: Using an object-based approach to quantify the spatial structure of reflectivity regions in Hurricane Isabel (2003). Part I: Comparisons between radar observations and model simulations. Mon. Wea. Rev., 146, 1319-1340, https://doi.org/10.1175/MWR-D-17-0077.1.

Miyamoto, Y., and T. Takemi, 2013: A transition mechanism for the spontaneous axisymmetric intensification of tropical cyclones. J. Atmos. Sci., 70, 112-129, https://doi.org/10.1175/ JAS-D-11-0285.1.

, and D. S. Nolan, 2018: Structural changes preceding rapid intensification in tropical cyclones as shown in a large ensemble of idealized simulations. J. Atmos. Sci., 75, 555-569, https://doi.org/10.1175/JAS-D-17-0177.1.

Munsell, E. B., F. Zhang, J. A. Sippel, S. A. Braun, and Y. Weng, 2017: Dynamics and predictability of the intensification of Hurricane Edouard (2014). J. Atmos. Sci., 74, 573-595, https:// doi.org/10.1175/JAS-D-16-0018.1.

NOAA/Atlantic Oceanographic and Meteorological Laboratory, Hurricane Research Division, 2018: Hurricane Michael 2018 missions. Accessed 20 December 2018, http://www.aoml.noaa.gov/ hrd/Storm_pages/michael2018/mission.html.

Nguyen, L. T., R. F. Rogers, and P. D. Reasor, 2017: Thermodynamic and kinematic influences on precipitation symmetry in sheared tropical cyclones: Bertha and Cristobal (2014). Mon. Wea. Rev., 145, 4423-4446, https://doi.org/10.1175/ MWR-D-17-0073.1.

Papin, P. P., L. F. Bosart, and R. D. Torn, 2017: A climatology of Central American gyres. Mon. Wea. Rev., 145, 1983-2000, https://doi.org/10.1175/MWR-D-16-0411.1.

Rappaport, E. N., J. L. Franklin, A. B. Schumacher, M. DeMaria, L. K. Shay, and E. J. Gibney, 2010: Tropical cyclone intensity change before U.S. Gulf Coast landfall. Wea. Forecasting, 25, 1380-1396, https://doi.org/10.1175/2010WAF2222369.1.

Reasor, P. D., and M. D. Eastin, 2012: Rapidly intensifying Hurricane Guillermo (1997). Part II: Resilience in shear. Mon. Wea. Rev., 140, 425-444, https://doi.org/10.1175/ MWR-D-11-00080.1.

, R. Rogers, and S. Lorsolo, 2013: Environmental flow impacts on tropical cyclone structure diagnosed from airborne Doppler radar composites. Mon. Wea. Rev., 141, 2949-2969, https:// doi.org/10.1175/MWR-D-12-00334.1.

Rios-Berrios, R., R. D. Torn, and C. A. Davis, 2016a: An ensemble approach to investigate tropical cyclone intensification in 
sheared environments. Part I: Katia (2011). J. Atmos. Sci., 73, 71-93, https://doi.org/10.1175/JAS-D-15-0052.1.

,,-- and $-2016 \mathrm{~b}$ : An ensemble approach to investigate tropical cyclone intensification in sheared environments. Part II: Ophelia (2011). J. Atmos. Sci., 73, 1555-1575, https:// doi.org/10.1175/JAS-D-15-0245.1.

— C. A. Davis, and R. D. Torn, 2018: A hypothesis for the intensification of tropical cyclones under moderate vertical wind shear. J. Atmos. Sci., 75, 4149-4173, https://doi.org/10.1175/ JAS-D-18-0070.1.

Rogers, R., P. D. Reasor, and S. Lorsolo, 2013: Airborne Doppler observations of the inner-core structural differences between intensifying and steady-state tropical cyclones. Mon. Wea. Rev., 141, 2970-2991, https://doi.org/10.1175/MWRD-12-00357.1.

, J. A. Zhang, J. Zawislak, H. Jiang, G. R. Alvey, E. J. Zipser, and S. N. Stevenson, 2016: Observations of the structure and evolution of Hurricane Edouard (2014) during intensity change. Part II: Kinematic structure and the distribution of deep convection. Mon. Wea. Rev., 144, 3355-3376, https:// doi.org/10.1175/MWR-D-16-0017.1.

Ryglicki, D. R., J. D. Doyle, D. Hodyss, and J. H. Cossuth, 2018a: The unexpected rapid intensification of tropical cyclones in moderate vertical wind shear. Part I: Overview and observations. Mon. Wea. Rev., 146, 3773-3800, https://doi.org/10.1175/ MWR-D-18-0020.1.

, Y. Jin, D. Hodyss, and J. H. Cossuth, 2018b: The unexpected rapid intensification of tropical cyclones in moderate vertical wind shear. Part II: Vortex tilt. Mon. Wea. Rev., 146, 3801-3825, https://doi.org/10.1175/MWR-D-18-0021.1.

,-- - D. Hodyss, J. H. Cossuth, Y. Jin, K. C. Viner, and J. M. Schmidt, 2019: The unexpected rapid intensification of tropical cyclones in moderate vertical wind shear. Part III: Outflow-environment interaction. Mon. Wea. Rev., 147, 29192940, https://doi.org/10.1175/MWR-D-18-0370.1.

Shimada, U., K. Aonashi, and Y. Miyamoto, 2017: Tropical cyclone intensity change and axisymmetricity deduced from GSMaP. Mon. Wea. Rev., 145, 1003-1017, https:// doi.org/10.1175/MWR-D-16-0244.1.

Shu, S., and L. Wu, 2009: Analysis of the influence of the Saharan air layer on tropical cyclone intensity using AIRS/Aqua data. Geophys. Res. Lett., 36, L09809, https://doi.org/10.1029/ 2009GL037634.

Tang, B., and K. Emanuel, 2012: A ventilation index for tropical cyclones. Bull. Amer. Meteor. Soc., 93, 1901-1912, https:// doi.org/10.1175/BAMS-D-11-00165.1.
Tao, D., and F. Zhang, 2019: Evolution of dynamic and thermodynamic structures before and during rapid intensification of tropical cyclones: Sensitivity to vertical wind shear. Mon. Wea. Rev., 147, 1171-1191, https://doi.org/10.1175/ MWR-D-18-0173.1.

Wadler, J. B., R. F. Rogers, and P. D. Reasor, 2018: The relationship between spatial variations in the structure of convective bursts and tropical cyclone intensification as determined by airborne Doppler radar. Mon. Wea. Rev., 146, 761-780, https://doi.org/10.1175/MWR-D-17-0213.1.

Zagrodnik, J. P., and H. Jiang, 2014: Rainfall, convection, and latent heating distributions in rapidly intensifying tropical cyclones. J. Atmos. Sci., 71, 2789-2809, https://doi.org/10.1175/ JAS-D-13-0314.1.

Zawislak, J., H. Jiang, G. R. Alvey III, E. J. Zipser, R. F. Rogers, J. A. Zhang, and S. N. Stevenson, 2016: Observations of the structure and evolution of Hurricane Edouard (2014) during intensity change. Part I: Relationship between the thermodynamic structure and precipitation. Mon. Wea. Rev., 144, 3333-3354, https://doi.org/10.1175/MWR-D16-0018.1.

Zhang, F., and D. Tao, 2013: Effects of vertical wind shear on the predictability of tropical cyclones. J. Atmos. Sci., 70, 975-983, https://doi.org/10.1175/JAS-D-12-0133.1.

Zhang, J. A., and R. F. Rogers, 2019: Effects of parameterized boundary layer structure on hurricane rapid intensification in shear. Mon. Wea. Rev., 147, 853-871, https://doi.org/10.1175/ MWR-D-18-0010.1.

,-- P. D. Reasor, E. W. Uhlhorn, and F. D. Marks, 2013: Asymmetric hurricane boundary layer structure from dropsonde composites in relation to the environmental vertical wind shear. Mon. Wea. Rev., 141, 3968-3984, https://doi.org/ 10.1175/MWR-D-12-00335.1.

—, J. J. Cione, E. A. Kalina, E. W. Uhlhorn, T. Hock, and J. A. Smith, 2017: Observations of infrared sea surface temperature and air-sea interaction in Hurricane Edouard (2014) using GPS dropsondes. J. Atmos. Oceanic Technol., 34, 1333-1349, https://doi.org/10.1175/JTECH-D-16-0211.1.

Zhou, L., S.-J. Lin, J.-H. Chen, L. M. Harris, X. Chen, and S. L. Rees, 2019: Toward convective-scale prediction within the next generation global prediction system. Bull. Amer. Meteor. Soc., 100 , 1225-1243, https://doi.org/10.1175/BAMS-D-17-0246.1.

Zhou, X., Y. Zhu, D. Hou, Y. Luo, J. Peng, and R. Wobus, 2017: Performance of the new NCEP global ensemble forecast system in a parallel experiment. Wea. Forecasting, 32, 1989-2004, https://doi.org/10.1175/WAF-D-17-0023.1. 